\title{
An alternative approach towards the knowledge production function on a regional level - applications for the USA and Russia
}

\author{
Jens K. Perret \\ Department of International Management, \\ Economics and Quantitative Methods, \\ International School of Management, \\ Im MediaPark 5c, 50670 Cologne, Germany \\ Email: jens.perret@ism.de
}

\begin{abstract}
A knowledge production function is used to account for the efficiency of an innovation systems; it provides a quantile regression estimation of the knowledge production function to account for a nonlinear relationship (efficiency) between knowledge inputs and knowledge output. Regional data for researchers, expenditures on R\&D and patent grants for the USA and the Russian Federation is used in two different designs. In both countries, groups of regions exist with smaller sized research systems that report significantly different dynamics and thus knowledge production functions than regions with larger sized research systems. In the USA, regions with small research systems report decreasing returns to knowledge inputs while region with large research systems report increasing returns to knowledge inputs thus efficiency is achieved in fostering larger regional innovation systems. In the Russian Federation, the effect is exactly the opposite; it is the smaller regional innovation systems that are most productive.
\end{abstract}

Keywords: Russian Federation; innovation system; knowledge production function; KPF; knowledge generation; quantile regression; regional economics; USA; Russia; panel data; econometrics; efficiency of knowledge production; knowledge economy; innovation; comparison of regional development.

Reference to this paper should be made as follows: Perret, J.K. (2018) 'An alternative approach towards the knowledge production function on a regional level - applications for the USA and Russia', Int. J. Innovation and Regional Development, Vol. 8, No. 1, pp.44-74.

Biographical notes: Jens K. Perret finished his studies in mathematics and economics and in 2013 he received his $\mathrm{PhD}$ at the University of Wuppertal in Germany. During his time as a Research Assistant, he has also been a researcher at the European Institute for International Economic Relations. Currently, he is working as a Professor for Economics and Statistics at the International School of Management in Cologne, Germany. His research interests include the economic development in the Russian Federation with a special focus its innovation system and dynamics of structural change in the European Union.

This paper is a revised and expanded version of a paper entitled 'An alternative approach towards the knowledge production function on a regional level applications for the USA and Russia' presented at 16th Conference of the Schumpeter Society, Montreal, Canada, 6-8 July 2016. 


\section{Introduction}

In 1992, Lundvall introduced the concept of the national innovation system (NIS) into economic literature providing a comprehensive frame of reference to analyse the innovation dynamics in economies. Following the OECD's 1999 report on NISs, regional innovation systems (RIS) are the essential building blocks of any NIS. The analysis of an NIS is therefore inherently of a regional nature. In this context the discussion of RIS has gained importance in recent years as on the one hand can be seen from publications like Rodríguez et al. (2014), Rodríguez and Navarro-Chávez (2015), Zemtsov et al. (2016b) and Bernhard (2016). On the other hand, the topic also become increasingly more important for policy makers be it Russian initiatives to strengthen specific regions (see Zemtsov et al., 2016a) or the smart specialisation strategy of the European Union which effects are studied for example in McCann and Ortega-Argilés (2015) or in relation to RIS by Lindberg and Jansson (2016). ${ }^{1}$

At the core of every NIS, two concepts are of central importance: the generation and the diffusion of innovations and ergo knowledge, on the one hand, inside the system itself and on the other across the system's borders.

The present study picks up on the aspect of knowledge generation in the context of the Russian Federation (RF) and the USA. A comprehensive analysis of the knowledge generation and transmission process in the RF can be found in Perret (2013). Comparable studies for the USA are for example, Varga (2000), Audretsch and Stephan (1999) or Ó hUallacháin and Leslie (2007). Over the last two decades, the RF experienced a transition from a Soviet centrally planned economy to a market economy. However, it can still not be considered a fully developed knowledge society comparable to Western European economies where the terms of knowledge society or knowledge economy can be interchanged with the term NIS. On the other hand, the USA is considered to be one of the world's leading knowledge economies and to have a very efficient and effective innovation system.

In this context, the USA and the RF offer an interesting comparison. They had a much different history and followed a different development path while also being politically and economically on different levels of development. An analysis of the USA and the RF therefore allows us to take a look at how an innovation system - or at least the knowledge generation mechanism - in this type of a developing economy under specific restrictions looks and works and how it compares to the innovation system of a highly developed knowledge society and analysed with the same methodology. Furthermore, this study can generate the first step in more broader comparison or offer an analytical template for the study of other BRICS countries or countries at a similar level of development and comparable economic characteristics like Indonesia or India.

Fritsch and Slavtchev (2006) argue that estimating a knowledge production function (KPF) allows to test the efficiency of an NIS. ${ }^{2}$ The link between knowledge inputs and knowledge output basically coincides with the knowledge generation process in an NIS. The KPF approach is thus a suitable tool to analyse the USA and the Russian innovation system - Audretsch et al. (2014) provide a concise overview on the links between knowledge and innovation.

While studies like Fritsch and Franke (2004) and Lee and Park (2005) or Wang and Huang (2007) operate on a firm basis, this study tackles the question from a regional perspective. In particular, this study does not consider single RIS separately but their 
summation into one single NIS with the RIS and their dynamics however still being present.

However, this study does not so much aim at simply applying the basic framework of the KPF to the USA and Russian data but tries to deduce in which areas the basic linear KPF framework needs adjustment to better fit the situation in the two countries and in which way the two countries differ from each other. While the basic idea of quantile regressions that is implemented is rather old, Koenker and Bassett (1978) has been the first to provide an applicable methodology the number of publications in economics implementing quantile regressions is still rather limited. In particular, regarding the study of NIS or RIS and this study potentially is the first one applying quantile regression in studying knowledge generation. Note that Mathew (2012) provides an analysis, using quantile regressions, that is comparable in same aspects to the one done in this study.

The study is structured in five sections. In the following Section 2, the idea of innovation systems is revisited and the difference as well as the linkage of RIS and the NIS are stressed. In succession in Section 3, the basic KPF is introduced.

In Section 4, at first the quantile regression approach is motivated via the estimation of a kernel density function for the patent activities in both countries and via the calculation of a transition matrix. In a second part, the quantile regression analysis is performed to account for the stability of regression coefficients and thus the linearity of the KPF and the potential of omitted variables. Using the regression results, a nonlinear version of the KPF specifically constructed around the present innovation data is deduced.

The study concludes in Section 5 with conclusions also picking up on policy and research implications.

\section{NIS and RIS}

A NIS or a RIS is a fuzzy term, therefore, a simple definition is hard to find.

The use of NIS as a basis for research on the development of countries started with the first broad use of the term in the studies by Lundvall (1992) and Nelson (1993) ${ }^{3}$ and is based in part on the study of Freeman (1987) on the development of the Japanese economy. In the more recent literature, the study of NISs has become increasingly more established, so that in his overview, Carlsson (2006) already accounts for approximately 750 studies on innovation systems. A second survey of the literature is available in Carlsson (2007), a recapture of the literature is therefore externalised to these surveys.

The regional perspective and the term RIS was introduced only shortly after the national perspective by studies like Cooke (1992), Asheim (1995), Asheim and Isaksen (1997) and more recently by Zabala-Iturriagagoitia et al. (2007), Cooke (2009) and Gust-Bardon (2015) that pick up on the local nature of knowledge and especially knowledge spillovers, which, as has been argued in previous sections, can be seen as mostly tacit, and therefore underline the importance of the region in comparison to the nation specifically. In the context of the RF, Pavlov (2012) and Zemtsov et al. (2016a) can be mentioned exemplary as Crescenti et al. (2007) can provide an example for the USA.

A more conclusive approach to the definition and spectrum of a NIS and the integration of the RIS into the NIS is given by the OECD (1999). Figure 1 recreates the OECD representation of an NIS. 
Figure 1 National innovation system

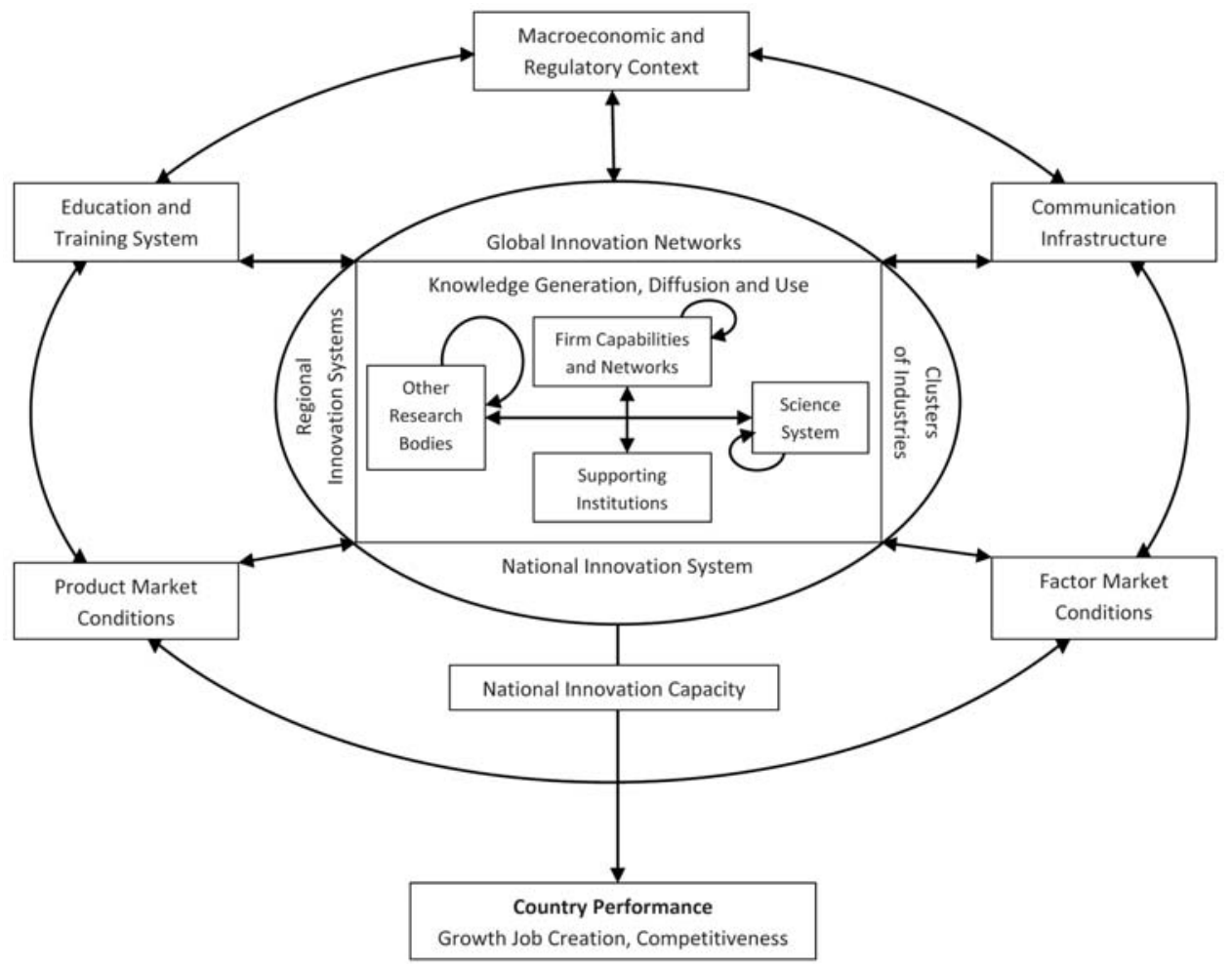

Source: Reproduced from OECD (1999)

The figure shows in detail that the focus of an NIS and thus an RIS lies in the research and development sector, which is seen as essential to the creation and diffusion of knowledge. This R\&D sector is embedded in an environment that encompasses the labour and goods markets as well as the education and the communication sector and the general macroeconomic environment. This environment however is shaped on a regional level and for example the national education system is the result from the aggregation of regional education systems. The clusters situated in the centre of the NIS are also inherently regional entities.

Starting from a similar point, Asheim and Gertler (2005) define an RIS, by referring to Asheim (1999), as the institutional infrastructure that supports innovations and is set in the production structure of a region.

While the basic idea behind them and their basic characteristics are the same especially when using the OECD multidimensional definition - an RIS is only part of an NIS, in the same way that a region is part of a nation.

For the course of this study, whose main background is the Russian and the USA innovation systems the OECD's definition of an NIS as well as the definition by Asheim and Gertler (2005) of an RIS are considered to be of prime importance. In particular since they stress that the RIS are essential building blocks of a NIS and any analysis of the NIS by necessity needs to be based on the RIS, their development, integration and interactions as for example via interregional knowledge transfers and factor movements. Especially 
the last aspect is considered by Perret (2015) and stresses the co-evolution of regions and thus the RIS.

While the discussion above centrally focuses at economic arguments the importance of a regional perspective becomes only stronger if a business perspective is included as well, since value and thus supply chains only in very rare instances are still intra-regionally set. Thus RIS are also impacted and linked via business cooperation and supplier ties generating an overlaying net of connections between the regions which drives the pull effects of regional development and specialisation.

In this study, the discussed effects, in particular the linkages between regions, are considered as well. Due to the nature of the estimation performed herein spatial effects of whichever kind could not be considered in the estimations. However, the following study is based on panel estimations (with no pooling of variables taking place) thereby automatically accounting in part for interaction effects and thus the links between the different RIS. We acknowledge that the study could have profited from studying specific regions and their RIS in detail. However, the number of regions under consideration and the, in part, limited timeframes (especially for the EPO patents of the RF) lead to a focus on the NIS and its overall structure, subsuming all RIS and their linkages.

\section{Methodology - the KPF}

\subsection{Introduction}

In analogy to traditional production functions which describe the relation between economic input and output factors, a KPF describes the relation between knowledge inputs on the one hand and knowledge output on the other. Therefore, with $K^{I}$ as knowledge inputs and $K^{O}$ as knowledge output, a KPF is a function $K^{O}\left(K^{I}\right)$. As knowledge inputs can be subsidised to a certain degree - e.g., researchers can be subsidised by additional expenditures on $R \& D$ as in the purchase of external knowledge - a KPF can be seen as a substitutional production function.

Additionally, a KPF does not have a theoretical maximum as the generation of knowledge is bounded only by the quantity of input factors.

It is thus reasonable to assume the form of a Cobb-Douglas-type production function when modelling a KPF:

$$
K^{O}=a \cdot K^{l \alpha} \cdot K^{l \beta}{ }_{2} \ldots
$$

This line of argumentation leads to the basic form of a KPF as discussed and used in a similar fashion by Griliches (1979) when introducing the KPF concept into economics. However, the functional form Griliches and succeeding researchers like Stephan et al. (2000), Acs et al. (2009), Savin and Winker (2012) or most recently Perret (2017) implemented has been of a much simpler form with only one (usually researchers) knowledge. The upcoming literature review summarises a number of studies that implemented KPF of this simpler design using only a single knowledge input. In this study only researchers are considered as the single input factor as well.

A KPF can however also take a different functional forms. For example, Bitzer (2003) suggests a different approach to modelling a KPF. Additionally, it might be reasonable to include spatial effects in the analysis of the KPF as well. This has been 
done for example by Perret (2013). One of the main aims of the present study is to ascertain whether the assumption of a linear or log-linear form of the KPF is suitable when using the underlying dataset.

The discussion about the most suitable way to approximate knowledge output is as old as the idea of the KPF itself. Griliches (1979) himself argued that the idea of using patent grants or applications is flawed, as patents only represent part of the codified knowledge. This link between patents and innovations is studied in more detail by Roper and Hewitt-Dundasa (2015) who argue that it might be a rather weak link.

However, in the absence of a more suitable indicator, this study uses the number of patent grants as an approximation of the stock of knowledge. Thus, it is in line with Verspagen and Schoenmakers (2004) who argue that patents can be seen as a noisy but usable approximation of the stock of knowledge.

Fritsch (2002) and Fritsch and Franke (2004) advocate the use of either researchers or R\&D expenditures as knowledge inputs, though not both at the same time, as a large share of the R\&D expenditures is used to pay for the researchers including both would lead to biases in the regression results. Thus, the basic KPF has the following form:

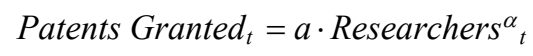

Abbreviating the patent grants with $P$ and the number of researchers with $R$ and taking the logarithm the function can be written as:

$$
\log (P)=\log (a)+\alpha \cdot \log (R)
$$

Admittedly, patents are not granted instantaneously. Thus, we assume a time frame of one year for knowledge to be produced that can be patented accordingly (In some sectors, like pharmaceuticals, the time frame might be much longer, while in other sectors, like food products, it can be much shorter).

If, finally, new knowledge is generated, it needs to be submitted to the patent office for appraisal.

According to official statements by the EPO or Rospatent the patenting process in the RF officially should take between six months and two years (see WIPO, 2012). For patent applications at the European Patent Office (EPO) one to two years can be seen as a reasonable assumption. 4

All told a time lag of two or three years might be a suitable assumption. While Fritsch and Slavtchev (2006) suggest that a three year lag offers the best alternative, Perret (2013) finds for the RF on a regional level a lag of two years to provide the best results.

So far it has been assumed that the KPF possesses constant coefficients $a$ and $\alpha$. Considering the quantile regression approach, this assumption can be tested and, considering it does not hold true, the assumption can be relaxed and $a$ becomes a function $a(P)$ of the patent grants and $\alpha$ a function $\alpha(P)$.

The functions can be estimated by acknowledging that the quantile regression approach delivers a set of coefficients for each quantile of the patents variable. Calculating those quantiles explicitly it becomes possible to link patent values (the quantiles of the patent variable) with the estimated coefficient values from the quantile regression. Regressing the patent quantiles against these coefficient values delivers an estimate of the functions $a(P)$ and $\alpha(P)$. 


\subsection{Linear and log-linear coefficients}

While a solution for arbitrary functions $a(P)$ and $\alpha(P)$ cannot be calculated explicitly, a simple but useful case is to assume them to be linear or log-linear in logarithmised terms, respectively.

Both functions thus have the following forms:

$$
\begin{aligned}
& a(P)=\exp \left(a_{1} \log (P)+b_{1}\right) \\
& \alpha(P)=a_{2} \log (P)+b_{2}
\end{aligned}
$$

The equation (1) can be logarithmised to read as follows:

$$
\log (a(P))=a_{1} \log (P)+b_{1}
$$

The KPK in this case reads as:

$$
\log (P)=a_{1} \log (P)+b_{1}+\left(a_{2} \log (P)+b_{2}\right) \log (R)
$$

The advantage is that this equation can explicitly be solved for the patents $P$ and therefore allows for an exacter deduction of the KPF (while using this type of it needs to be noted that the degree of exactness of this methods depends on the functional form of the coefficients and their potential to be noted in an at least partial linear fashion) - note that in cases where in the original formulation a logarithm, aside from logarithm naturalise, has been implemented, the exponential function needs to be subsidised by a corresponding power function.

$$
P=\exp \left(-\frac{b_{2}}{a_{2}}\right) \exp \left(-\left(\log (R)+\frac{a_{1}-1}{a_{2}}\right)^{-1}\right)^{\frac{b_{1} a_{2}+b_{2}-a_{1} b_{2}}{a_{2}^{2}}}
$$

While this equation seems at first to be bulky and unwieldy, in the course of the following analysis it will be useful to have it in this form.

\subsection{Literature review}

As this study concerns itself with questions relating to the development and efficiency of NIS and RIS it is in line with the studies by Lundvall (1992), Nelson (1993) and Freeman (1987) who introduce the idea behind the NIS to economics. Instead of repeating herein an overview of publications related to the study of NIS and RIS it is referred to Carlsson (2006, 2007) who provide first overview on these studies. For RIS it is especially the studies by Cooke (1992), Asheim (1995) and Asheim and Isaksen (1997) that shift the perspective from the national to the regional level and recently Crescenti et al. (2007), Zabala-Iturriagagoitia et al. (2007), Cooke (2009), Pavlov (2012), Gust-Bardon (2015) and Zemtsov et al. (2016a) who provide examples for the application of the idea behind RIS.

Considering the formal definition of a RIS and its integration into the NIS, OECD (1999) provides a suitable overview that is detailed by Asheim (1999) and Asheim and Gertler (2005).

While this is not the first study to estimate a KPF [the idea being introduced by Griliches (1979)], among studies which have tested the KPF for specific regions or 
sectors, there are the only four studies with a direct focus on the RF, Roud (2007), Savin and Winker (2012) and Perret $(2013,2017)$. For the USA, the basis is much broader with Varga (2000), Audretsch and Stephan (1999), Ó hUallacháin and Leslie (2007) and Branstetter (2001) (the USA and Japan) providing an excerpt of studies with the respective focus.

Other studies on the topic can be roughly categorised into one of four categories.

In the first category, studies take a look at a specific group of countries: Madsen (2008) (OECD) or Buesca et al. (2010) (Europe/EU).

A second category consists of those studies that consider only individual countries. Besides the above cited ones for the USA and Russia, there are, for example, studies by Ponds et al. (2010) (Netherlands), Buesca et al. (2006) (Spain), Andersson and Ejermo (2003) (Sweden), Ranga et al. (2003) (Belgium), Conte and Vivarelli (2005) (Italy), Fritsch and Franke (2004) (Germany), Wagner (2006) (Germany), Fischer and Varga (2003) (Austria), Masso and Vahter (2008) (Estonia) and Wu (2009) (China).

The third category is comprised of studies on specific sectors: Zucker et al. (2007) (nanotechnology), Stephan et al. (2000) (biotechnology), Ramani et al. (2008) (biotechnology and food) and Pardey (1989) (agriculture).

Finally, the fourth group consists of those studies that have a more general focus unrelated to any sector or region. This category includes: Abdih and Joutz (2005) (total factor productivity), Masso and Vahter (2008) (total factor productivity) and Anselin et al. (1997) (state-level vs. metropolitan-level) as well as, from a more theoretical perspective, Griliches and Mairesse (1998) and Acs et al. (2009).

As this study implements a KPF to test the efficiency of the Russian and the USA NIS it situates itself in the above introduced context. As the amount of studies focussing on the RF is limited, especially in regards to studying its efficiency by use of a KPF, this study provides additional insights in this context. Additionally, while comparative studies exist no study on NIS or RIS exist that applies the same methodology to the USA and Russia and provides a comparative analysis of these two nations. Third, most lines of research described above, when implementing a KPF [Bitzer (2003) being a rather example], assume a linear or log-linear form for the KPF and thus try to fit the data to the model and not the model to the data. In this context this study provides not only new insights for the USA and the RF but also new insights on the use of quantile regressions in the study of NIS and RIS.

\section{Analysis of the KPF}

\subsection{Variable design}

The basic KPF only include researchers, therefore the problem of omitted variables is almost endemic, as shown by Perret (2013).

Considering that a significant part of the knowledge generation process is omitted, if only basic inputs are observed, the classical KPF usually needs to be extended through the introduction of additional variables. However, as will be shown in the next section extending the KPF by including additional variable does not always solve the nonlinearity of the coefficients only alleviates it a little. For the RF, it will be shown in how far extending the KPF affects the stability of coefficients. Thus possible additional input factors need to be considered here as well. 
Some of the aspects considered herein have already been implemented in other studies on the KPF approach. Following a broader perspective, as with the study by Asheim and Gertler (2005) or the seminal work on innovation systems by Lundvall (2010), where the KPF is described as a statistical representation of the NIS, underlines that a NIS cannot be described in its entirety by only one variable and region specific fixed effects.

While patents as indicators of knowledge output were available since 1987 from the EPO, Rospatent only began publishing patents on a regional level in 1997. Additionally, using a version of the Patstat (the single source for patent data regarding EPO patents) database from Spring 2008 only allows to account for patents up to 2006. To limit biases due to data selection and as data for the dependent variables is only available since 1994, EPO patents were considered from 1994 to 2006 while Rospatent patents were considered from 1997 to 2012. For all dependent variables data has been available from 1994 to 2012. Even though it is recognised that limiting the study to the year 2012 does exclude recent development trends from a purely formal perspective it is very convenient to stop in 2012. Until 2012, the regional layout across the RF has been relatively stable and all changes that did occur were only intra-regional or of a nominative nature. Stopping in 2012, excludes the regional re-allocations between Moscow city and the Moscow Oblast as well as having to argue the exclusion of the two de-facto objects of Crimea and Sevastopol - if data were available at all - as they would significantly bias the results.

The argument might be raised that EPO patent data - being used to represent Russia's internationally oriented innovation system - limits the results of the analysis to those firms that have a general interest in the European market. However, considering that the correlation between the patents from the EPO and the patents from Rospatent across all regions for the ten years from 1997 to 2006 amounts to 0.9245 it can be assumed that the distribution of international EPO patents across regions mirrors that of domestic Rospatent patents which should be less biased towards the European market. Furthermore, this high correlation might be considered a first indicator that both parts of the Russian NIS are connected. Nevertheless, a suitable way to complement this study would be to use triad patents or at least Japanese or Chinese patent data, thereby covering for possible patenting in the Far Eastern regions which might be more oriented towards Asian markets than towards the European market.

Patents used herein represent patent grants and are assigned to specific years via their priority dates. As data from Rospatent is only available on a regional basis, EPO patents have been aggregated to the regional level using the official Russian classification of regions. In particular the Nenetsia Autonomous Okrug is considered part of the Arkhangelsk Oblast and the Yamalia and Khantia-Mansia Autonomous Okrugs are considered parts of the Tyumen Oblast.

The analysis is focussed on the Russian perspective therefore only patents from inventors of Russian origin are considered and the assignment of patents to regions is performed on the basis of the inventors' addresses.

In all cases the base variable is the number of researchers (All variables implemented in this section enter the regression in logarithmised terms, except for shares. It can be argued that scaling the researcher variable by using per capita values would be more suitable for the overall validity of the estimation, to ensure comparability with other studies of KPF however, absolute numbers are considered.). It is complemented by control variables to account for the relative economical size of the regions and the 
regional real GRP with base year 1995 - note that integrating the GRP also allows one to control for business cycle effects.

In different studies (i.e., Kim, 2010) four channels of direct and indirect knowledge transfers are introduced - tacit knowledge spillovers via inventor or researcher movements, codified knowledge spillovers via patent citations and spillovers via trade and FDI. Since they provide to the generation of knowledge, they are considered as suitable controls. With tacit knowledge already accounted for by the researcher variable, the number of students per region adds to this aspect while accounting in some part for the institutional framework as well, as student numbers in Russia are highly correlated with universities. The regional imports and the foreign direct investment inflows are added to the regression accounting for spillovers via trade and FDI. Imports impact innovativeness as it relieves pressure from domestic firms to innovate and provide products for their home market. Lichtenberg et al. (1998) stress that it is not so much the intensity of imports, but the distribution of the countries of the origin of imports that matters, however these effects are not accounted for in this study. Furthermore it is noted that a feedback relation between the generation of knowledge via patents and FDI flows seems highly likely even though respective tests do not yields corresponding results in this context. As patent data has only been available for a restricted time horizon, the consistent calculation of a stock of patents as proxy for the availability of codified knowledge has not been possible.

Furthermore, the market structure is included in the model via the shares of small and medium enterprises - an indicator in order to argue in line with Schumpeter (1911) that small and medium enterprises are more innovative than large enterprises and thereby generate more new knowledge. Additionally, the link between the market structure and the innovative output, the innovativeness of a region, is argued in detail already by Mansfield (1981), Cohen et al. (1987), Rothwell (1989) and Link and Bozeman (1991). Following the ideas presented in Ayyagari et al. (2003), SME are correlated to the institutional framework of the region and the business environment, a higher share of SME indicates a more open and free business environment, while a lower share might be an indicator for a large share of the informal economy.

The number of government personnel is included to approximate the amount of corruption taking place - but also to account for government presence in general. As a proxy for corruption, the size of the government accounts indirectly for institutional efficiency. The choice of government personnel as an approximation for corruption has been made as a number of surveys taken in Russia ${ }^{5}$ show that the highest amount of corruption is perceived in contexts with government officials like the police or members of the judicial and the education system. A higher number of government employees thus indicate a larger potential for corruption, which by itself would be harmful for knowledge generation as capital flows could be used more efficiently elsewhere. Secondly, state-owned businesses are considered to be less efficient than private businesses and therefore less innovative as well (see Netter and Megginson, 2001). On a region-wide level a higher amount of government personnel might be an indicator for more state-owned businesses as well and therefore for more inefficiency and fewer innovations - as with the researchers, it can argued that it might be more prudent to use per capita values instead.

The amount of oil and gas exploited in each region is included for two reasons. Studies show on the one hand that the level of corruption is much higher in this sector 
than in any other, i.e., Leite and Weidmann (1999) argue that corruption depends on natural resources, while Tompson (2006), a little less drastically, links corruption to large state-owned firms, which in Russia persist in the oil and gas industry. Furthermore, the sector itself is less innovative than other sectors. Note in this context, also the proclaimed negative relation between resource endowments and economic growth which, in the literature, is referred to as the resource curse. See for a discussion of this phenomenon for example of Auty (1993).

Finally, the base model includes the amount of exports and an indicator for economic openness - the indicator being calculated as the relation of the sum of exports and imports against the GRP. Even though the exports are as well part of the openness indicator, multicolinearity is no problem in this context. The influence of exports can be motivated as export oriented firms are usually more successful, since they are more accustomed to competition. They need to be more modernised and more innovative to compete internationally and therefore are more likely to generate new patents. This argument can be backed up with studies by Podmetina et al. (2011) who show that export oriented firms are generally more innovative than firms oriented only towards their home market. Furthermore, Silva et al. (2010) as well as the literature cited in Wagner (2007) argue along the lines of learning-by-exporting and therefore the growth of knowledge through exporting.

A similar line of argumentation holds for the openness indicator, as regions that are more open to the world economy are confronted more with international competitive pressure and are therefore forced to innovate more. The inclusion of the openness indicator might, however, not generate significant additional information as it basically replicates the effects of exports, imports and GRP in a composite form.

In addition, Torkkeli et al. (2009) stress the importance of FDI and trade flows on knowledge absorption and therefore the absorptive capacity in the RF. Including these trade variables into the model thereby automatically accounts in part for the absorptive capacity. All monetary variables including the GRP, the exports and imports as well as the FDI enter the model in real terms with the base year 1995.

Besides the data for EPO patents which has been collected from the Patstat database all other Russian data has been collected from the annual publications series Regionii Rossii (Rosstat, 2003, 2008, 2011, 2012) published by the Russian statistical office.

For the USA, it needs to be stressed that numbers on researchers were not available on a regional level and are subsidised by numbers of expenditures on R\&D. A preliminary correlation analysis of both statistics on the national level shows that both statistics are highly correlated with a correlation coefficient of 0.9946 . Additionally, using a simple OLS regression on both data series shows a positive linear relation with $R^{2}$ $=0.9893$ and an F-statistic of $F=1941.62$. As collecting the same amount of data for the USA as has the case for Russia would necessarily lead to the use of a number of data sources. This heterogeneity of sources might generate additional biases in the data. Additionally, some datasets have not or not freely been available on a regional level. Therefore, in the upcoming analysis this study is restricted in using only the basic design for KPF in the USA case.

All USA data has been collected from the online databases of the USA National Science Foundation as well as with regards to patents from the USPTO database. 


\subsection{Kernel density estimation and Markov transition matrices}

Quah (1995) motivates and uses kernel density estimation to account for clubs in the context of interregional convergence. The same methodology is then taken up by other researchers in the same field to test whether economic convergence occurs uniformly across all regions or whether regions convergence to different steady states. The same approach can, however, also be applied to the question of whether within a group of countries there exists a common innovation system or if the countries, or in the present case regions, need to be divided into subgroups - with each subgroup forming its own innovation system.

In Quah (1995), he identifies different clubs via distinct peaks in the density function. However, it needs to be taken into account that in contrast to the question of convergence with the KPK the identification might not be as clear and distinct. One would expect to find a rather fat tail instead of a second peak, in particular since USA and Russian regions by themselves are rather heterogeneous. Thus, in this study we accept the presence of significantly fat tails as sufficient motivation against assuming the existence of only one common set of regions and thus of only one common innovation system. The kernel density estimation thus provides an answer to the applicability of a panel quantile regression estimator on the whole datasets.

As can be seen for both cases i.e., the USA as well as the Russian case, the countries do not report a clear second peak but both of them report rather fat tails. In the right figure for the RF a very slight second peak is visible, however, it is no very distinct. Nonetheless, the two parts of Figure 2 are seen as first evidence in favour of additional heterogeneity in the context of the patenting activities and thus of the existence of more than one innovation system in each country. Note that in this figure only the case of Russian domestic patents at Rospatent is considered as it is later on shown that with Russian patents at the EPO no problems regarding the constancy of coefficients arises and thus quantile regression analysis in this case is not necessary and therefore no motivation thereof is needed.

Besides the number of innovation systems present, a second important question that needs to be asked beforehand is whether the adherence to one of the innovation systems is fixed over time or whether a high number of regions switch from one group to the other in the course of the analysis. This question can be studied easily by implementing the idea behind Markov transition matrices. As the panel quantile regression methods does not differentiate between changes across time or across regions, to assure that the results can be interpreted easier it is important for the regional structure of the innovation systems or rather the RIS to remain stable over time. Fingleton (1997) for example did some comparable work in the context of analysing economic convergence.

The two parts of Figure 3 show that while the borders of the innovation systems in the USA and in Russia are not impervious to change, relatively speaking only a small number of regions change their adherence from one quartile to another. Additionally, all switches that do occur usually occur from one quartile to the next higher or lower quartile. Analogously to the kernel density estimation, only Rospatent patents were considered for the RF. 
Figure 2 Kernel density estimation for (a) US and (b) Russian patent grants (see online version for colours)

Kernel Density Plot

Used hOpt $=189.447583103561$

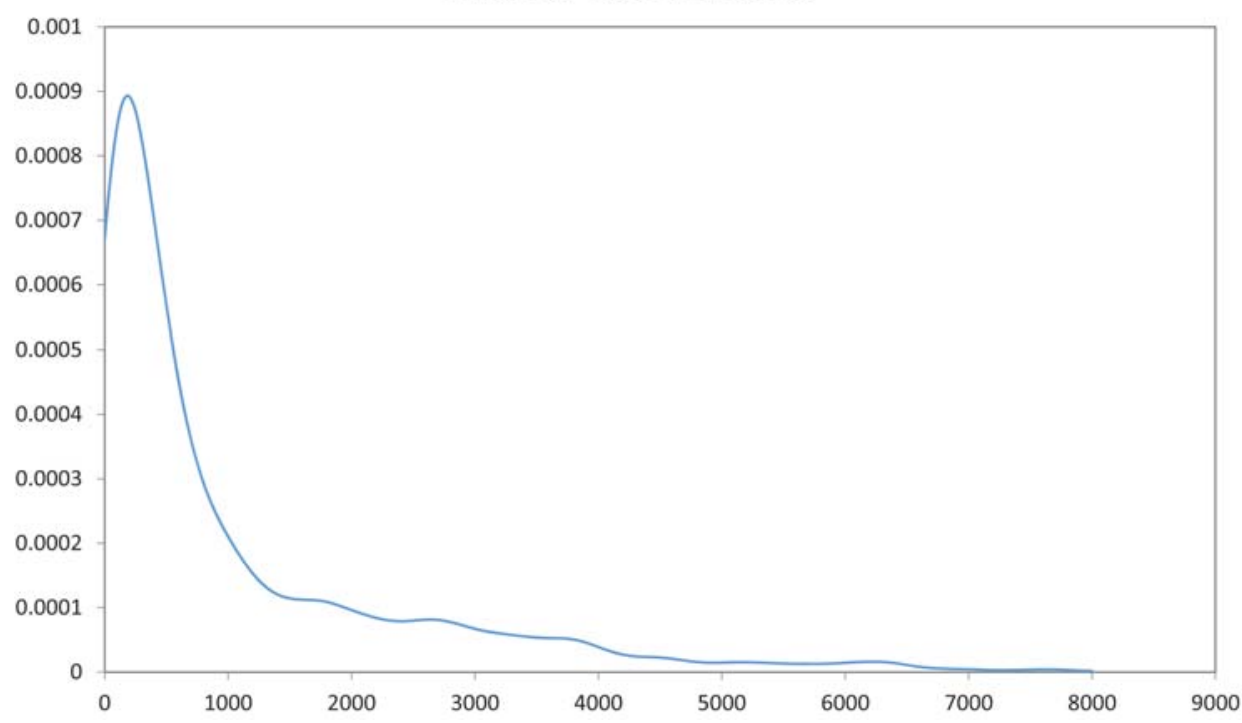

(a)

Kernel Density Plot

Used hOpt $=\mathbf{3 0} .0287547975118$

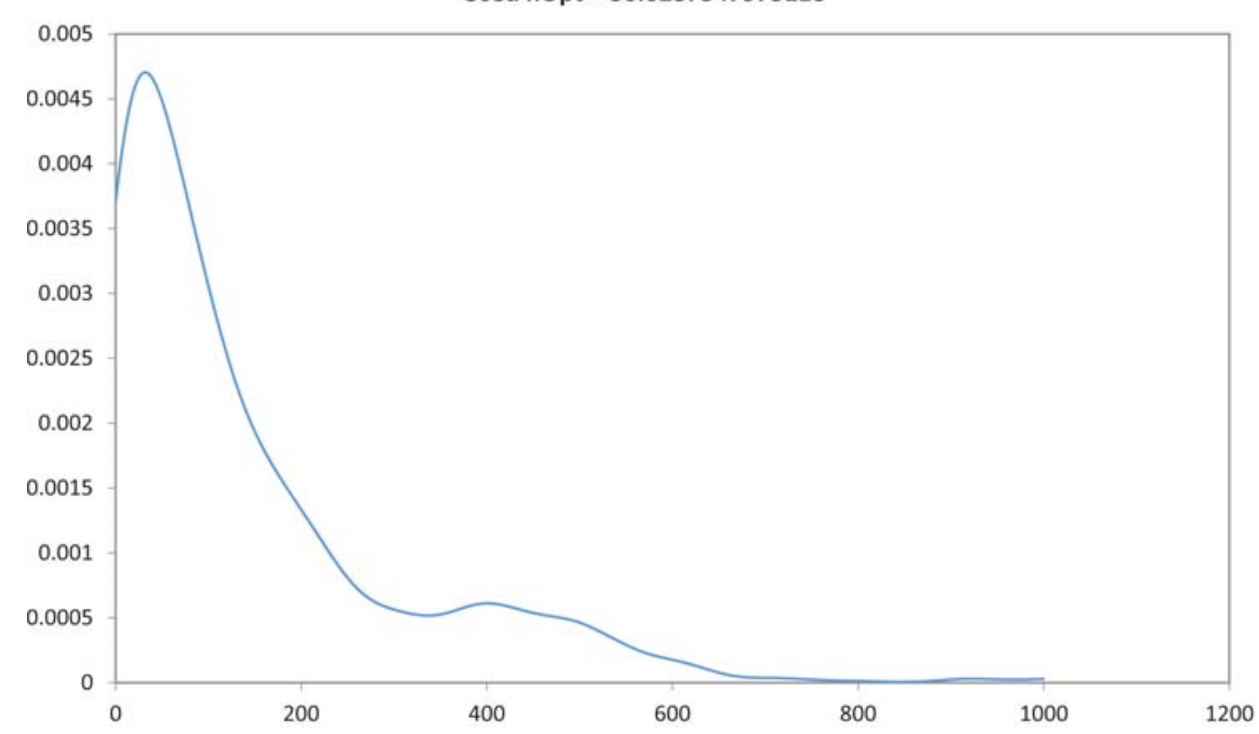

(b) 
Figure 3 Markov transition matrices for (a) US (1963-2007) and (b) Russian (1997-2012) patent grants (see online version for colours)

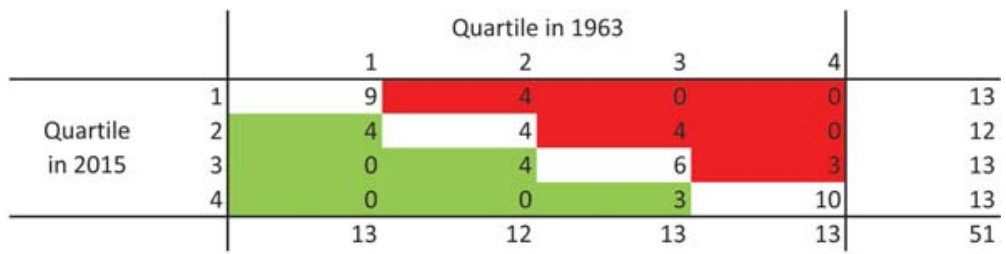

(a)

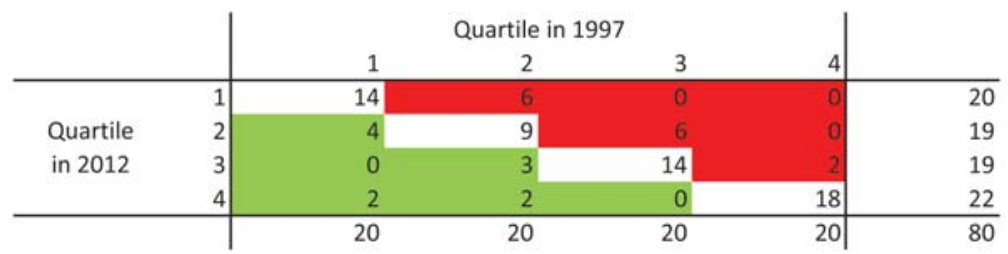

(b)

It can thus be reasoned that the specific groups within the two countries are relatively stable. This is an important insight regarding potential quantile regression analysis as too much volatility among regions would imply that the result could not be used to draw conclusions regarding any specific group of regions, as the groups would not remain consistent over time.

\subsection{A quantile regression approach}

In contrast to classical mean-based estimation techniques, quantile regression allows to account for a number of additional aspects. The most important feature is that it allow to account for unequal variations caused by omitted variables - in other words, quantile regression models allow for different slopes, different coefficients calculated at given parts of the underlying distribution. Additionally, although not part of this study, results from quantile regression models can be used to generate weights for mean-based estimation techniques to counter biases of a nonlinear relation. Considering that Perret $(2013,2017)$ find indications that using a classical design of the KPF for Russia does not deliver stable results using a quantile regression approach seems the most prudent choice to provide definite proof on the functional form of the Russian KPF. This becomes even more important since no other studies concern themselves with answering this question.

In this section, a panel quantile estimator as motivated by the work of Koenker and Bassett (1978) and introduced by Koenker (2004) is used to account at first for the RF (and in the second part for the USA) for different slopes, on the one hand in the context of the basic KPF, on the other in the context of an extended KPF. ${ }^{6}$ The extended KPF includes, besides the researchers, all of the variables motivated in the beginning of this section. Estimations have been carried out for a two and a three years time lag. In both cases the results look almost identical. Therefore, only the results for two years time lag are presented herein. In both cases, Rospatent patent data is used in the analysis. ${ }^{7}$ 
Figure 4 Quantile regression for RP patents - (a) intercept and (b) slope coefficient of basic model (see online version for colours)

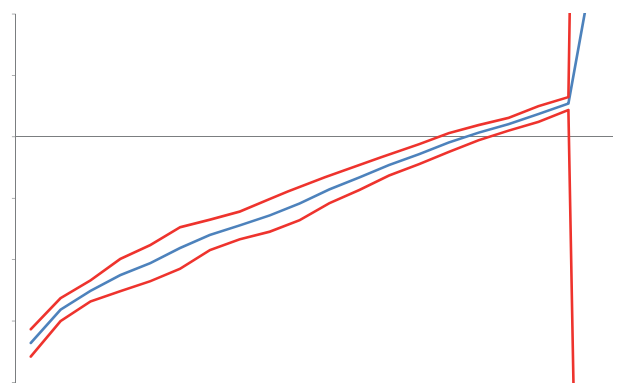

(a)

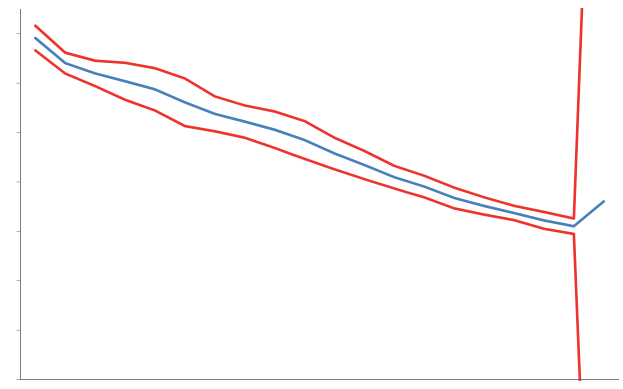

(b)

Figure 4 shows the different coefficients calculated for equally weighted quantiles with a distance of five percentage points. Additionally, the figure contains a $95 \%$ confidence interval generated via 500 bootstrap repetitions. The right part of the figure in particular reveals that the relation between researchers and Rospatent patents is not linear. In specific, the results show that at lower quantiles the coefficients are larger and are steady declining indicating that the researcher variable exerts not only a change in the means of the patent variable but on its variance as well.

Applied to the underlying data, this signifies that decreasing returns to scale concerning patenting - for the input of research personnel are present across the regions of the RF.

Figure 5 Quantile regression for EPO patents - (a) intercept and (b) slope coefficient of basic model (see online version for colours)

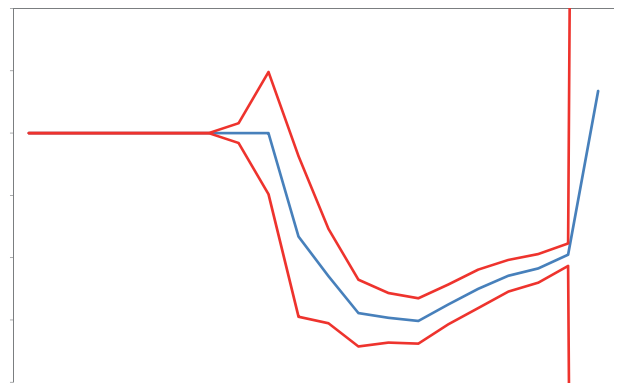

(a)

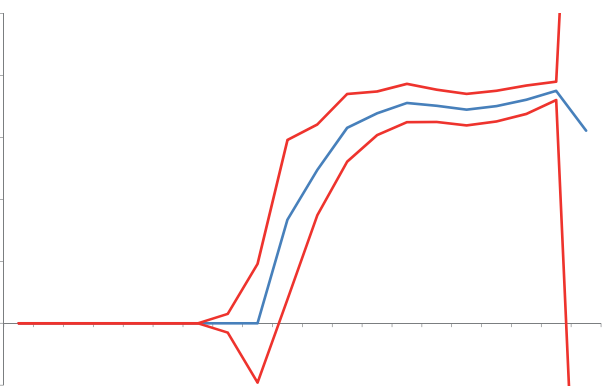

(b)

The constant left part of both parts of Figure 5 can be readily explained by the presence of zero-inflation in the data as a large number of regions did not own an European patent. Disregarding the values for the lower quantiles up to the $50 \%$ quantile, it is interesting to note that for the higher quantiles the intercept is more or less linearly increasing and the slope is constant.

This signifies that the researcher variable exerts an impact on the mean of the patenting variable - there are constant returns to scale of the researcher inputs when considering EPO patents. 
Furthermore, this result indicates that the basic KPF suffices when trying to describe international oriented patenting activity across the Russian regions. In other words, the single most important factor for patenting at the EPO is being one of the regions with large research centres and thus possessing the largest research potential, i.e., that which matters most on an international level.

Figure 6 Quantile regression for RP patents - (a) intercept and (b) slope coefficient of extended model (see online version for colours)

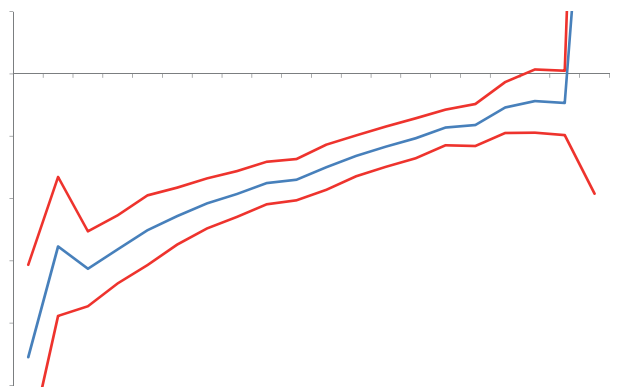

(a)

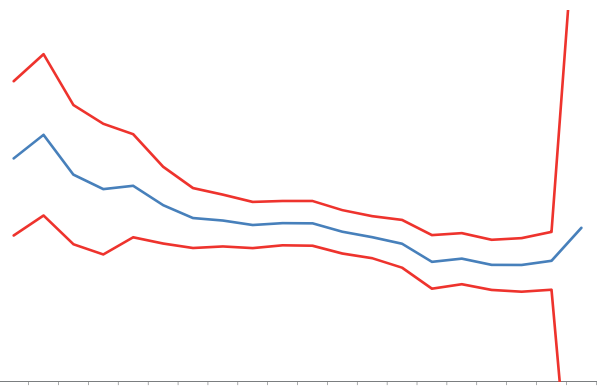

(b)

Switching from the basic to the extended model, it can be seen from Figure 6 that while the results inherently do not change between the basic and the extended model, the right part of the figure shows that the decrease in the slope in less pronounced, however, it does not disappear completely. The additional variables thus capture, while not all of it, at least a significant part of the unexplained variance in the dependent variable.

However, as has already been mentioned in Perret (2013) and in the beginning of this section, there is still a large part of unexplained variance due to the lack of relevant variables or due to a nonlinearity of the model. In this context the linearisation of the coefficients introduced in the methodology section can be used to account for this specific type of nonlinearity.

For EPO patents, similar to the results for the basic model, starting from the $60 \%$ quantile the slope can be considered to be more or less constant, while in comparison to Figure 5 it becomes more rugged. This indicates that while extending the model might have a positive effect concerning the intercept, the layout of the basic model might already suffice and yield more stable results than the extended model (figures for the extended model are not included here).

Summarising, when considering Rospatent data the results mirror those of a typical location-scale model with a decreasing slope parameter indicating that the model still contains a lot of unexplained variance that needs to be accounted for via additional variables.

Furthermore, as especially consistent Russian regional panel data, aside from the one already implemented in the context of the extended model, is hard to come by, it seems a prudent choice to use the results above to generate weights for usage by standard panel estimators to counter the bias that is still present even in the extended model.

For the international perspective and considering EPO patents, the figures point to the conclusion that the basic KPF already suffices and extending the model might only destabilise the slope coefficients. In this context, in the next section only the KPF using 
Rospatent patent data is considered any longer as the basic KPF design suffices for the EPO-based one.

Figure 7 Quantile regression for US USPTO patents - (a) intercept and (b) slope coefficient of basic model (see online version for colours)

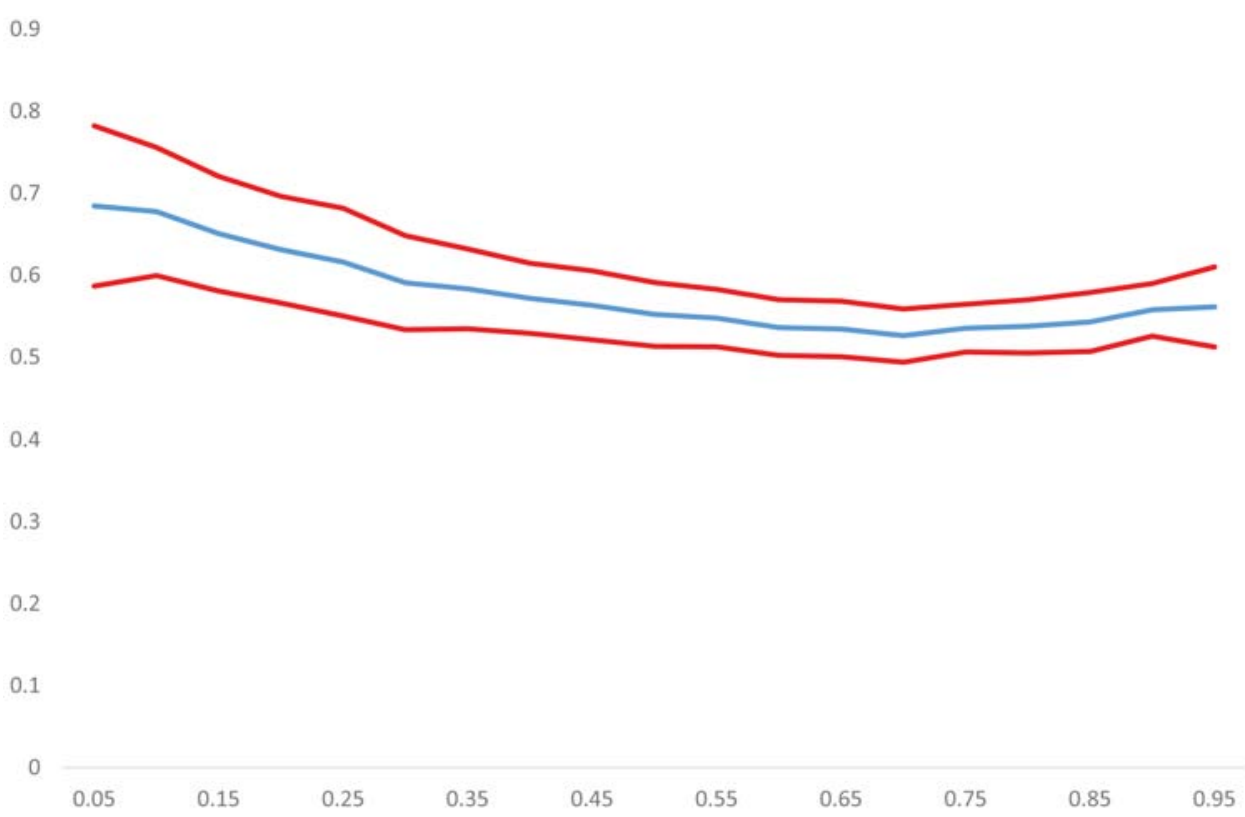

(a)

2.5

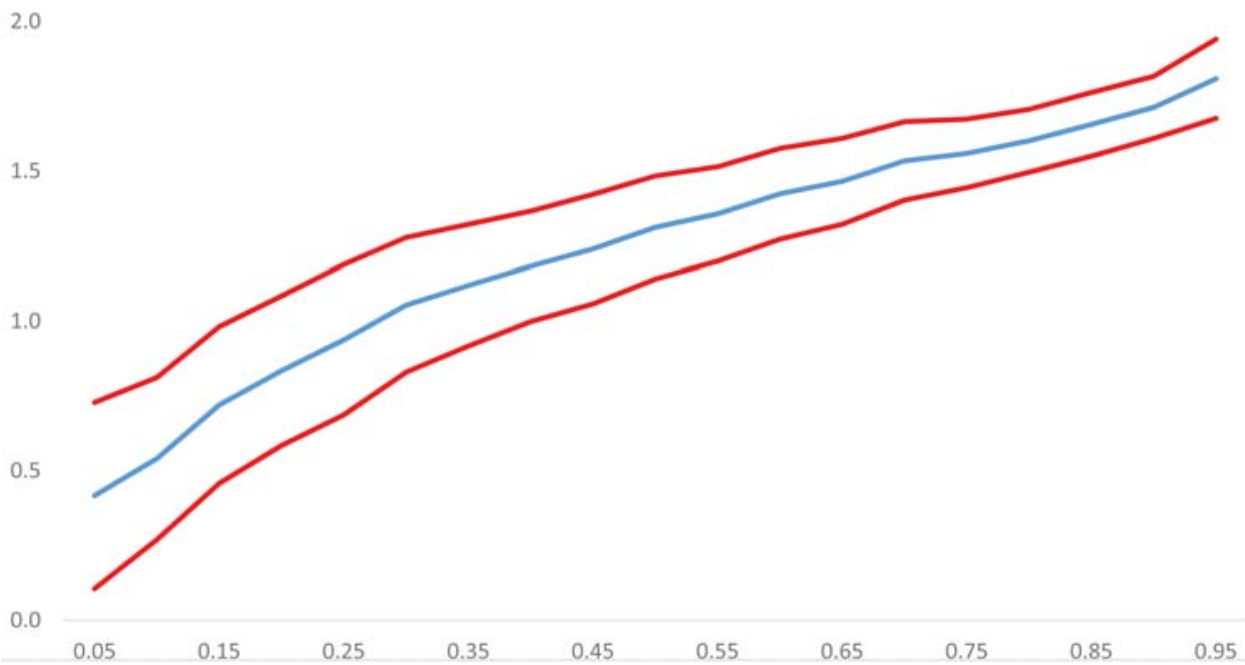

(b) 
Nonetheless, in a second step, we might still consider the results for the USA patent data at the USPTO and expenditures on R\&D.

Figure 7 summarises the results of the quantile regression, run this time with data for the USA. ${ }^{8}$

The results are comparable to those from the Russian case with patents from Rospatent. The only difference is that the intercept in this case is monotonously increasing while the slope parameter represents a more or less quadratic relationship. Thus, the nonlinear and non-constant slope parameter in particular gives rise to the need to analyse the relationship in more detail as well.

\subsection{Extending the basic KPK}

In the previous section, it has been shown that adding variables to the KPF design might help to alleviate some of its design flaws but not all of them. Therefore, in this section, the results from the previous section, in particular those for the basic cases, are taken and used to construct an alternative KPF design for the USA and the RF, respectively.

Referring to Figures 4 and 7, it can be seen that the coefficients, with the exception of the USA slope parameter, show a more or less linear pattern. However, it is not certain that the quantiles are equidistant. Thus, as motivated above in Figures 8 and 9, quantiles for the patent variable have been calculated and were plotted against the coefficient values.

Figure 8 Quantile regression for Rospatent patents (distance corrected) - (a) intercept and (b) slope coefficient

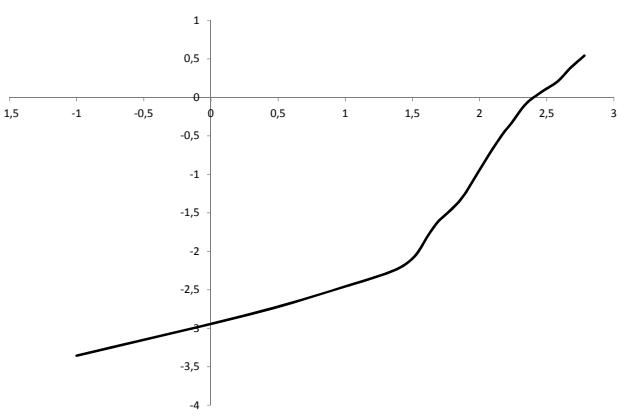

(a)

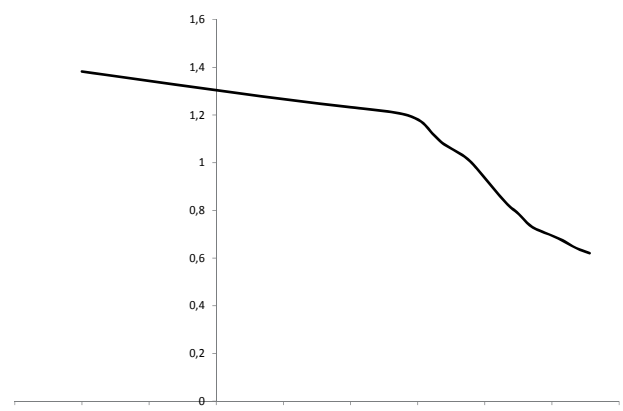

(b)

While these plots can be decently approximated by a polynomial of the fifth order, it seems to be more prudent to assume both coefficients to be piecewise linear functions with a break at either approximately 0.9 or 1.4 , respectively. Considering that these values refer to the logarithmised patent numbers (to the base of ten), the break would occur at approximately eight or 25 patents.

Comparable to the results presented in Figure 7, Figure 9 illustrates that the coefficient for the USA intercept can be approximated by a linear function while the best fit for the slope parameter can be achieved via a quadratic equation. For reasons of simplicity and being able to solve the KPF analytically, the slope parameter here is also approximated by a piecewise linear function. 
Figure 9 Quantile regression for USPTO patents (distance corrected) - (a) intercept and (b) slope coefficient (see online version for colours)

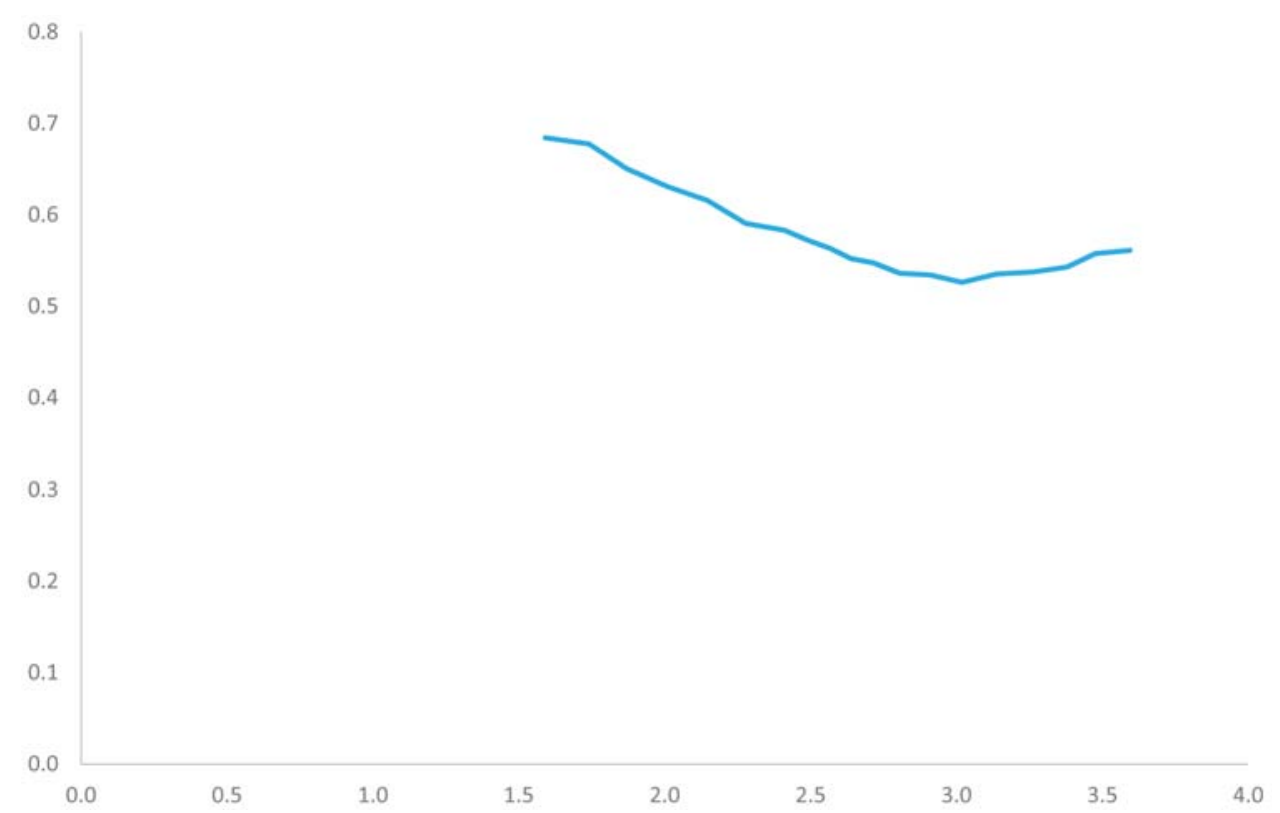

(a)

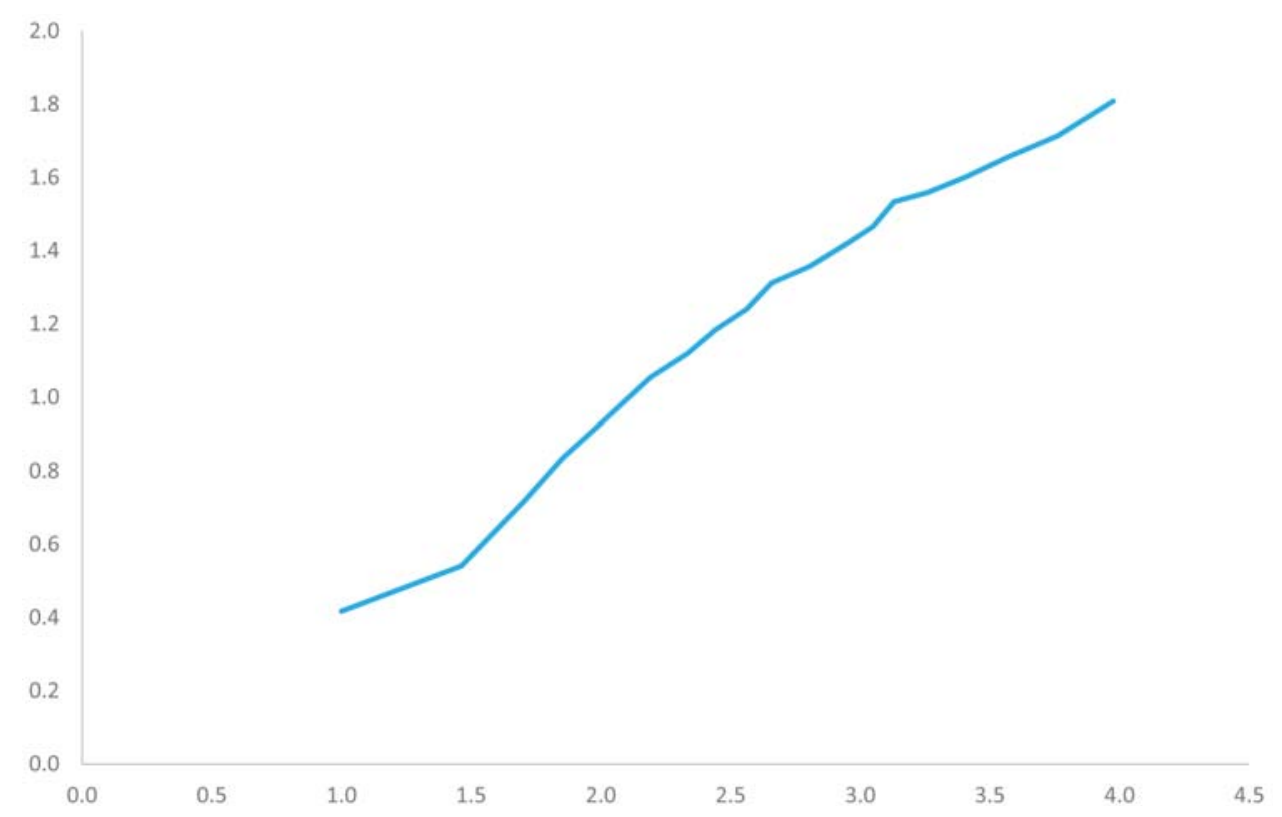

(b) 
Thus, using linear functions for approximating the slope and intercept can be used in both cases, i.e., for the USA and for the RF. Therefore, the necessary steps discussed below relating to the RF are exemplary, the same steps are performed analogously for the USA. In the end, only the final KPF function will be reported and illustrated for the US.

Figure 10 reports the intercept $\log (a(P))$ and the slope parameter $\alpha(P)$ for the upper linear piece of the KPF (for eight or more patents) while Figure 11 reports the functions for the lower linear pieces. The figures also include a regression line for the functions to graphically illustrate the fit. A figure for the case with a break at 25 patents is not presented separately as the results more or less copy Figures 10 and 11. Table 1 furthermore underlines the similarity of both cases.

Figure 10 Piecewise regression of (a) intercept and (b) slope coefficients - upper piece

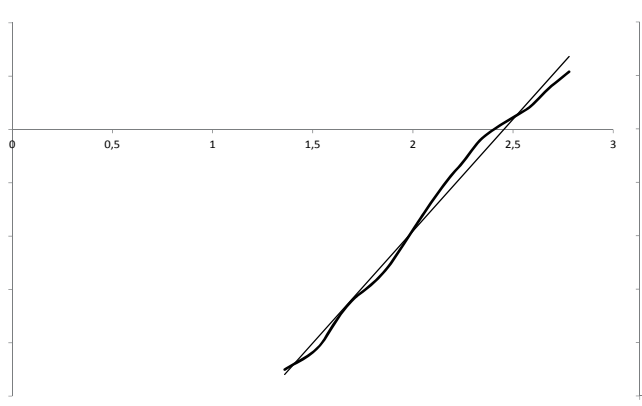

(a)

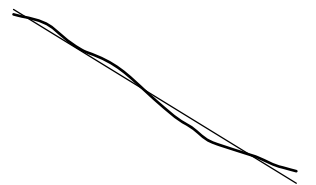

(b)

Figure 11 Piecewise regression of (a) intercept and (b) slope coefficients - lower piece

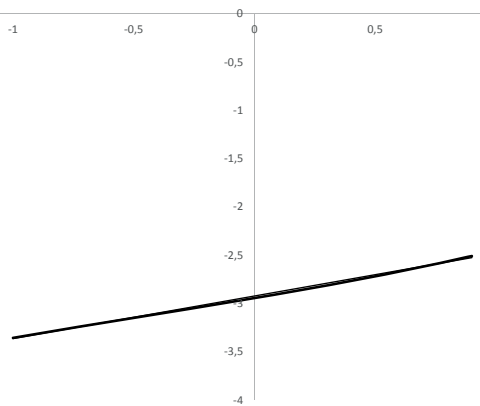

(a)

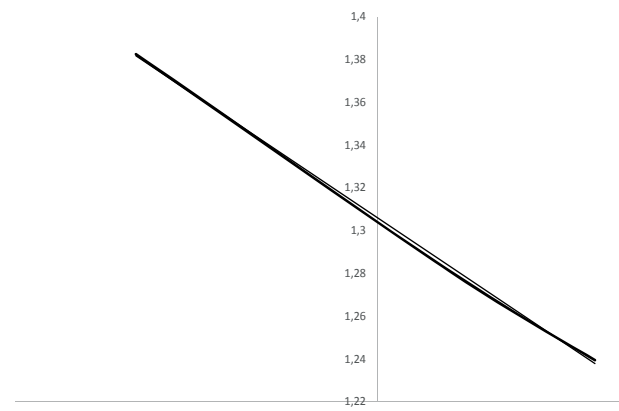

(b)

Table 1 reports the equations for the regression lines as well as the $\mathrm{R}^{2}$ statistics and the significance levels according to an F-test (Asterisks are used to signify significance. ${ }^{*}$ is an error margin of $10 \%, * *$ of $5 \%$ and $* * *$ of $1 \%$ ) both for the case with a break at eight patents and a break at 25 patents; in both cases for the upper as well as for the lower parts of the piecewise functions. 
Table 1 Regression results: intercept-and slope-functions

\begin{tabular}{lcccc}
\hline & Intercept & Slope & $R^{2}$ & F-test sig. level \\
\hline 8 patents & & & & \\
Slope upper piece & 1.8488 & -0.458 & 0.9841 & $* * *$ \\
Intercept upper piece & -5.1514 & 2.0991 & 0.9902 & $* * *$ \\
Slope lower piece & 1.306 & -0.0757 & 0.9992 & $* *$ \\
Intercept lower piece & -2.9229 & 0.4414 & 0.9976 & $* *$ \\
25 patents & & & & $* * *$ \\
Slope upper piece & 1.864 & -0.4645 & 0.9816 & $* * *$ \\
Intercept upper piece & -5.1888 & 2.1153 & 0.9882 & $* *$ \\
Slope lower piece & 1.3066 & -0.0743 & 0.999 & $* *$ \\
Intercept lower piece & -2.9137 & 0.4634 & 0.9953 & \\
\hline
\end{tabular}

Using these estimates of the intercept and slope functions and referring to the results of the exercise in Section 2, the KPF for the break at eight patents can be given as (it is taken into account that piecewise functions are regularly defined via the independent variable and not as has been the case here via the dependent variable.):

$$
P=\left\{\begin{array}{cc}
10^{17.2523} 10^{-165.9186(\log (R)+7.3791)^{-1}} & \text { for } P<25 \\
10^{4.0367} 10^{-1.5604(\log (R)-2.3998)^{-1}} & \text { for } P<25
\end{array}\right.
$$

To test for stability, the alternative break at 25 patents has been considered as well. Using the same procedure as above, the resulting KPF is given below. It can be seen that both pieces are comparable to the equation above.

$$
P=\left\{\begin{array}{cc}
10^{17.5855} 10^{-166.2188(\log (R)+7.2221)^{-1}} & \text { for } P<25 \\
10^{4.0129} 10^{-1.5353(\log (R)-2.4011)^{-1}} & \text { for } P<25
\end{array}\right.
$$

Figure 12 KPK, (a) lower and (b) upper piece

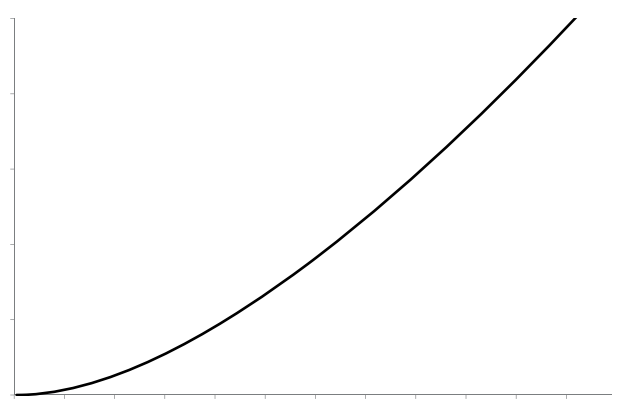

(a)

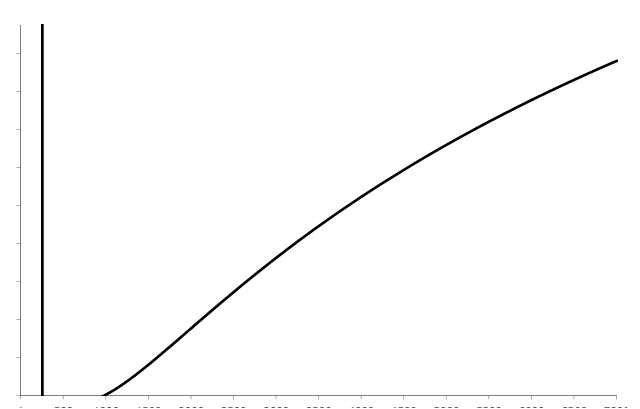

(b)

If equation (10) is plotted it results in Figure 12. The figure illustrates that there is a definitive gap in the definition. For the approximate interval $R(980 ; 1110)$ this KPF is not defined. Returning to the raw data, this translates into 72 observations which equals 
about $4.74 \%$ of total observations. Switching to the original version with a break at eight patents, the gap would shift to the approximate interval $R \in(585 ; 790)$ which translates into 107 observations which equal about $7.04 \%$ of total observations.

To close these gaps in the definition consider that the intercept and the slope function have been deconstructed into two disjoint functions. Following this logic, it becomes evident that the two parts of the function need an artificial link to connect both of them. This artificial link needs to be a patent value between eight and 25 . To construct this value, the average of the coefficients for both intercept and both slope function are taken to construct an average KPK which reads as follows:

$$
P=\left\{\begin{array}{cc}
10^{17.4189} 10^{-166.0687(\log (R)+7.3006)^{-1}} \quad \text { Lower Part } \\
10^{4.0248} 10^{-1.5479(\log (R)-2.4005)^{-1}} \quad \text { Upper Part }
\end{array}\right.
$$

Both parts of the resulting KPF are then equalised. Solved for the number of researchers results in a quadratic equation:

$$
\log ^{2}(R)-7.383 \log (R)+13.0816=0
$$

This equation sports two solutions for $R$. The first solution is situated at $R=897.188$ resulting in a number of patents of $P=16.6947$. The second solution is situated at $R=26,921.324$ resulting in a number of patents of $P=1,828.673$. As the number of patents is assumed to be between eight and 25 the second solution is discarded and it is assumed that the first solution describes the true break in the KPF. While this procedure makes the KPF continuous at the value $R=897.188$ it still remains non-differentiable. This design flaw needs to be remarked upon as the basic KPF has been noted in its log-linear form and the logarithm as well as the first order derivative are linked to the growth rate of the function. This problem, however, will not be treated in the present study.

The final KPF is given in Figure 13 by the continuous line. The dotted line gives the traditional basic KPF as deduced by Perret (2013). It can be seen that the traditional form overestimates patent output for regions with smaller research systems while it underestimates the output for regions with larger research systems (Note that in both cases a fixed effects estimator has been implemented and thus the resulting KPFs are comparable.).

Figure 13 Fully combined KPF versus traditional form KPF-Russia

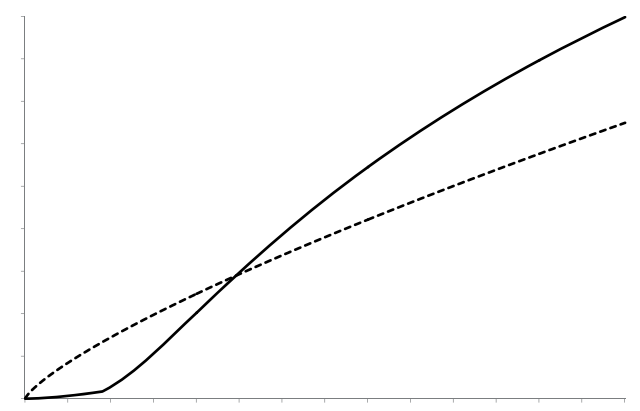


The quantile regression analysis only delivers information on the fact that regions with less developed (smaller) research systems, as measured via the number of active researchers, innovate differently. This detailed estimation however shows that in the less developed regions the marginal rate of research is much higher (and indeed increasing) than in regions with more developed (larger) research systems where the marginal rate of research is actually decreasing. In light of the typical design of a KPF as a Cobb-Douglas-type production function the form of the upper part of the function with decreasing returns to scale of research is not surprising; only the overall design of the function deviates from the theoretical basic KPF model not so much the underlying assumptions about its form. It is rather the lower part of the KPF with increasing returns to scale that surprises.

Returning to the deliberation that the Russian regional research and innovation systems are influenced significantly by cultural and societal effects, it seems plausible that once an innovation system reaches a certain size its potential for rent-seeking opportunists becomes obvious and their entrance into the innovation system reduces its effectiveness.

The threshold for a change in the structure of the innovation system as seen above lies at a size of around 900 researchers which refers to approximately $44.8 \%$ of all observations (note that these observations relate mostly to specific smaller regions which report consistently small values and are not limited to the years of the 1990s and thus to effects of the transition recession). This result gives hope insofar as it shows that a lot of Russia's regions are sporting an innovation system with increasing marginal rates of research and therefore offer a suitable basis to finally start on the path to a more sustainable economic development beyond natural resources.

Switching from the analysis of the Russian case to the USA case, it can be restated that the steps performed for the USA case basically mirrors the Russian case with the only exception being that the intercept function remains identical for both the upper and the lower part of the function. Thus, the final function reads as:

$$
P= \begin{cases}10^{0.8712 \log (R)-0.0631} 10^{-0.1185 \log (R)-0.5079} & \text { Lower Part } \\ 10^{0.3408 \log (R)-0.0631} 10^{-0.0612 \log (R)-0.5079} & \text { Upper Part }\end{cases}
$$

The equation shows that the structure for the KPF for the USA is inherently similar to the one for Russia. The main difference becomes obvious when the function is plotted together with the classical version of the KPF, that results from a fixed effects GMM estimation of the function.

When comparing the new USA and the new Russian KPF, two aspects are worth mentioning.

First, it is quite obvious that the first part of the USA' KPF shows decreasing returns to scale, a declining function, while the second part of the US' KPF shows increasing returns to scale, an inclining function. In other words, this means that for the USA regions, a certain size of the research sector is essential to avoid decreasing returns to scale.

For the RF, as discussed already above, the picture is the exact opposite. The first half, regions with small research systems, report increasing returns to scale while the second half, regions with bigger research systems, report decreasing returns to scale. It can thus be stated that the dynamics and potential efficiency gains via the innovation and research systems work exactly opposite in the USA and in Russia. 
Relating this to economic policy means that innovation and knowledge-based growth, the archetypical approach to sustainable growth, via investments in the research infrastructure and investments in $\mathrm{R} \& \mathrm{D}$, seem to be a suitable beneficial long-term solution for the USA. Contrarily, for the RF, investments that enlarge research systems and attract researchers might in the long run be harmful for the efficiency of the RIS. Thus, realising growth through innovations and research policy will be much harder for Russia than for the USA.

Figure 14 Fully combined KPF versus traditional form KPF-USA

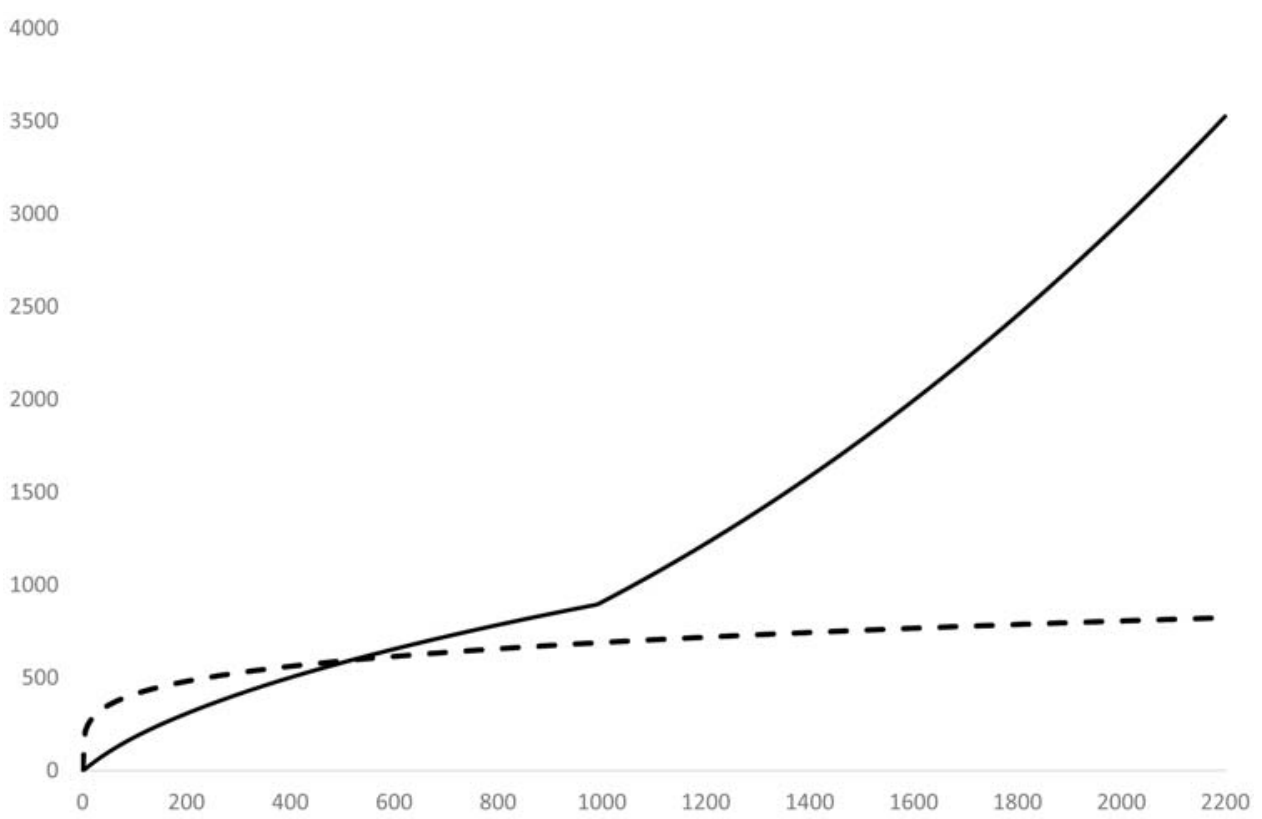

Contrary to the last paragraphs, a second aspect worth mentioning highlights commonalities between the USA and the Russian innovations systems. In both cases the critical point at which the efficiency of the innovation system changes lies at approximately 900 researchers. While the amount of patents these researchers generate, i.e., the efficiency of the innovation system differs, the number of researchers is rather stable and begs the question of whether this is just a statistical artefact or if it could be reduced to some basic underlying characteristics of innovation systems per se.

As a side-note, it is worth mentioning that in light of the still ongoing sanctions of the Western countries (as of early 2016) which hit high-tech imports in particular, the goal, as stated by President Putin, to restructure the Russian economy and foster its NIS and thus its RIS, becomes even more important for an economic turn-around. Assuming that, and despite a time lag of approximately three to four years which exists between the results of this paper and the reality, hope still persists that the potential of smaller regions with less developed innovation systems in particular might (if fostered correctly by the policy makers) have a significant impact on regional and thus national development. 


\section{Conclusions}

In the present study, the aim has been to shed additional light on the structure of the KPF - describing the relation between knowledge inputs and outputs.

While previous analyses focussed on fitting data to the KPF layout, this study can be seen as a first step in trying to allow the KPF structure to be more accommodating to the underlying data and thereby offering a better description of the structure of the respective NIS.

In the analysis, a panel quantile regression approach has been used to account for the nonlinearity of the relation between researchers or expenditures on $R \& D$, respectively, and patents. For Russia, it has been shown that, for the patents at Rospatent, decreasing returns of scale for the input of researchers exist which diminish when the basic KPF model is extended by additional variables. For patents at the EPO starting from the $50 \%$ quantile - due to considerable zero-inflation - a stable linear relation exists. Thus, on an international scale the classical KPF design actually suffices for the RF, however, not on a national scale.

Comparing the results of this study to comparable studies as those listed in the literature review it can be argued that one of the main contributions of this study can be found in showing that the application of the KPF design as introduced by Griliches is neither fitting for the RF as a representative transition country nor for a developed knowledge economy like the USA when considering the NIS and the generation of nationally important knowledge. Therefore, results from previous studies need to be considered carefully as it is highly likely that they as well over or underestimate the efficiency of the knowledge generation process in small and large regions - according to the size of the RIS. This study in particular contributed to the existing literature by showing that a KPF needs to be flexible enough to fit to the underlying data.

Decreasing returns to researcher input signify that regions with a large developed research system work less efficiently than regions with smaller research institutions. The goal of innovation politics should therefore aim at abolishing the inefficiency of large research centres. A second way to proceed can be seen in fostering the potential of regions with smaller, less developed innovation systems which, however, work more efficiently, it has been shown that this refers to at least about $45 \%$ of all observations and, in light of the fact that the RIS are rather path-dependent, it can roughly be translated into $45 \%$ of all regions. This would seem to call for a decentralisation of the innovation system, however, taking the developments of the last decade into account, this does not seem to be the aim of policy makers in Russia.

While not made explicit by this study, these results might indicate existing problems of corruption and institutional failure which increase with the size of the research sectors. A detailed analysis of this problem is, however, not a part of this study and, considering the data used herein, also not possible. It could, however, be a possible topic for future research.

For the USA, it has been shown that the opposite case holds true and starting at the same threshold (with regard to the patents granted per region) the innovation system reports increasing returns to scale for the research input. Thus, for the USA, a growth oriented research policy will in the long run be more sustainable and beneficial.

The results also show that the classical KPF design fits the underlying data worse than the flexible design implemented in this study, it especially underestimates the 
efficiency of large research systems and leads to wrong assumptions especially regarding large, elite research regions and established RIS.

Thus, this study contributed to the literature insofar as it provided a comparative analysis of the efficiency of the Russian and the USA innovation systems and has established that both systems behave inherently different; an insight that would not have been possible if the classical form of the KPF had been employed. Most studies on the topic of innovation systems focus on the USA and Europe which both could be assumed to function comparatively. Thereby this study also has shown that studying the Russian innovation system and other comparable systems the established methodology cannot just be copied but needs to be refitted to the special characteristics of these systems. This insight, while already of academic importance, becomes even more relevant if transferred to policy making. Due the different designs of the KPFs Russian innovation policy needs to be inherently different from US innovation policy and it might not be beneficial to copy established policies from the US.

An interesting results that bears the potential for a more in-depth analysis is the threshold of 900 researchers and the corresponding patent numbers, especially as with regards to the patent numbers it holds for both the USA and the RF. A future study might decide whether this is a characteristic shared by other countries besides the RF and the USA as well and which are the reasons for the threshold to be situated at this point.

An additional question that remains open and might offer incentives for future research is whether the results remain comparable if the view is switched from the NIS that is constructed from the different RIS to that of a RIS consisting of different firms. In this context, it would be interesting to deduce how the threshold of 900 researchers determined in this study translates to the firm perspective and whether a threshold as such can be found on the firm level at all. In addition to this, it could be studied whether the firm level in the RF and the USA copy the results from the regional level. In particular, if in the RF a small research department works more efficiently than a large one, thereby, contributing to management support as in the strategic planning of the size of the R\&D department.

Thus, the results of this study generate valuable insights for policy makers on the regional and national level in regards to the development of the RIS, especially with regards to its size.

\section{Acknowledgements}

The author would like to thank Mr. David Hanrahan for editorial support and the two anonymous reviewers for their inputs and comments.

\section{References}

Abdih, Y. and Joutz, F. (2005) Relating the Knowledge Production Function to Total Factor Productivity: An Endogenous Growth Puzzle, IMF Working Paper, WP/05/74.

Acs, Z.J., Braunerhjelm, P., Audretsch, D.B. and Carlsson, B. (2009) 'The knowledge spillover theory of entrepreneurship', Small Business Economics, Vol. 32, No. 1, pp.15-30.

Andersson, M. and Ejermo, O. (2003) Knowledge Production Function in Swedish Functional Regions 1993-1999, CESPRI Working Paper, WP n. 139. 
Anselin, L., Varga, A. and Acs, Z. (1997) 'Local geographic spillovers between university research and high technology innovations', Journal of Urban Economics, Vol. 42, No. 3, pp.422-448.

Asheim, B.T. (1995) 'Regionale innovasjonssystem - en sosialt og territorielt forankret teknologipoli-tikk', Nordisk Samhallsgeografisk, Vol. 20, pp.17-34.

Asheim, B.T. (1999) 'Interactive learning and localised knowledge in globalising learning economies', GeoJournal, Vol. 49, No. 4, pp.345-352.

Asheim, B.T. and Gertler, M.S. (2005) 'The geography of innovation: regional innovation systems', in Fagerberg, J., Mowery, D.C. and Nelson, R.R. (Eds.): The Oxford Handbook of Innovation, pp.291-317, Oxford University Press, Oxford.

Asheim, B.T. and Isaksen, A. (1997) 'Locations, agglomeration and innovation: towards a regional innovation system in Norway', European Planning Studies, Vol. 5, No. 3, pp.299-330.

Audretsch, D. and Stephan, P. (1999) 'How and why does knowledge spill over in biotechnology?', in Audretsch, D. and Thurik, R. (Eds.): Innovation, Industry Evolution, and Employment, pp.216-229, Cambridge University Press, Cambridge.

Audretsch, D. Lehmann, E. and Wright, M. (2014) 'Technology transfer in a global economy, The Journal of Technology Transfer, Vol. 39, No. 3, pp.301-312.

Auty, R.M. (1993) Sustaining Development in Mineral Economies: The Resource Course Thesis, Routledge, London.

Ayyagari, M., Beck, T. and Demirgüc, A. (2003) Small and Medium Enterprises Across the Globe: A New Database, World Bank Policy Research Working Paper, 3127.

Bernhard, I. (2016) 'Innovation focusing on regional development in a European context - towards a new research agenda', International Journal of Innovation and Regional Development, Vol. 7, No. 1, pp.1-19.

Bitzer, J. (2003) 'Technologische spillover-e ekte als determinanten des wirtschaftswachstums', Volkswirtschaftliche Schriften, Vol. 532, Duncker \& Humblot, Berlin.

Branstetter, L.G. (2001) 'Are knowledge spillovers international or intranational in scope?: Micro-econometric evidence from the US and Japan', Journal of International Economics, Vol. 53, No. 1, pp.53-79.

Buesca, M., Heijs, J. and Baumert, T. (2010) 'The determinants of regional innovation in Europe: a combined factorial and regression knowledge production function approach', Research Policy, Vol. 39, No. 6, pp.722-735.

Buesca, M., Heijs, J., Martinez Pellitero, M. and Baumert, T. (2006) 'Regional systems of innovation and the knowledge production function: the Spanish case', Technovation, Vol. 26, No. 4, pp.463-472.

Carlsson, B. (2006) 'Internationalization of innovation systems: a survey of the literature', Research Policy, Vol. 35, No. 1, pp.56-67.

Carlsson, B. (2007) 'Innovation systems: a survey of the literature from a Schumpeterian perspective', in Hanusch, H. and Pyka, A. (Eds.): Elgar Companion to Neo-Schumpeterian Economics, pp.857-871, Edward Elgar, Cheltenham.

Carmagni, R. (1991) 'Local milieu, uncertainty and innovation networks: towards a dynamic theory of economic space', in Carmagni, R. (Ed.): Innovation Networks: Spatial Perspectives, pp.121-142, Belhaven Press, London.

Carvalho, N., Carvalho, L. and Nunes, S. (2015) 'A methodology to measure innovation in European Union through the national innovation system', International Journal of Innovation and Regional Development, Vol. 6, No. 2, pp.159-180.

Cohen, W.M. and Levin, R.C. Mowery, D.C. (1987) 'Firm size and R\&D intensity: a re-examination', The Journal of Industrial Economics, Vol. 35, No. 4, pp.543-565.

Conte, A. and Vivarelli, M. (2005) One or Many Knowledge Production Functions? Mapping Innovative Activity Using Microdata, IZA Discussion Paper, 1878.

Cooke, P. (1992) 'Regional innovation systems: competitive regulation in the new Europe', Geoforum, Vol. 23, No. 3, pp.365-382. 
Cooke, P. (2009) 'Regionale innovationssysteme, cluster und die wissensökonomie', in Blättel-Mink, B. and Ebner, A. (Eds.): Innovationssysteme: Technologie, Institutionen und die Dynamik der Wettbewerbsfähigkeit, pp.87-116, VS, Wiesbaden.

Crescenti, R., Rodr guez-Pose, A. and Storper, M. (2007) 'The territorial dynamics of innovation: a Europe-United States comparative analysis', Journal of Economic Geography, Vol. 7, No. 6, pp.673-709.

Fingleton, B. (1997) 'Specification and testing of Markov chain models: an application to convergence in the European Union', Oxford Bulletin of Economics and Statistics, Vol. 59, No. 3, pp.385-403.

Fischer, M.M. and Varga, A. (2003) 'Spatial knowledge spillovers and university research: evidence from Austria', The Annals of Regional Science, Vol. 37, No. 2, pp.303-322.

Freeman, C. (1987) Technology Policy and Economic Performance: Lessons from Japan, Pinter, London.

Fritsch, M. (2002) 'Measuring the quality of regional innovation systems: a knowledge production function approach', International Regional Science Review, Vol. 25, No. 1, pp.86-101.

Fritsch, M. and Franke, G. (2004) 'Innovation, regional knowledge spillovers and R\&D cooperation', Research Policy, Vol. 33, No. 2, pp.245-255.

Fritsch, M. and Slavtchev, V. (2006) 'Universities and Innovation in Space', Industry and Innovation, Vol. 14, No. 2, pp.201-218.

Griliches, Z. (1979) 'Issues in assessing the contribution of R\&D to productivity growth', The Bell Journal of Economics, Vol. 10, No. 1, pp.92-116.

Griliches, Z. and Mairesse, J. (1998) 'Production functions: the search for identification', in Strom, S. (Ed.): Econometrics and Economic Theory in the 20th Century: The Ragnar Frisch Centennial Symposium, pp.169-203, Cambridge University Press, Cambridge.

Gust-Bardon, N.I. (2015) 'The structural and functional analysis of innovation systems: outline of the Polish case', International Journal of Innovation and Regional Development, Vol. 6, No. 1, pp.31-60.

Kim, M.J. (2010) 'Corruption and economic growth', EACGS Conference.

Koenker, R. (2004) 'Quantile regressions for longitudinal data', Journal of Multivariate Analysis, Vol. 91, No. 1, pp.74-89.

Koenker, R. and Bassett Jr., G. (1978) 'Regression quantiles', Econometrica, Vol. 46, No. 1, pp.33-50.

Lee, H-Y. and Park, Y-T. (2005) 'An international comparison of R\&D efficiency: DEA approach', Asian Journal of Technology Innovation, Vol. 13, No. 2, pp.207-222.

Leite, C. and Weidmann, J. (1999) Does Mother Nature Corrupt? Natural Resources, Corruption, and Economic Growth, IMF Working Paper, WW/99/85.

Lichtenberg, F.R. and van Pottelsberghe de la Potterie, B. (1998) 'International R\&D spillovers: a comment', European Economic Review, Vol. 42, No. 8, pp.1483-1491.

Lindberg, M. and Jansson, A.B. (2016) 'Regional social innovation - pinpointing socially inclusive change for smart, inclusive and sustainable growth in European regional development policy', International Journal of Innovation and Regional Development, Vol. 7, No. 2, pp.123-140.

Link, A.N. and Bozeman, B. (1991) 'Innovative behavior in small-sized firms', Small Business Economics, Vol. 3, No. 3, pp.179-184.

Lundvall, B-A. (1992) National Innovations Systems: Towards a Theory of Innovation and Interactive Learning, Pinter, London.

Lundvall, B-A. (Ed.) (2010) National Systems of Innovation: Toward a Theory of Innovation and Inter-active Learning, Anthem Press, London.

Madsen, J.B. (2008) 'Semi-endogenous versus Schumpeterian growth models: testing the knowledge production function using international data', Journal of Economic Growth, Vol. 13, No. 1, pp.1-26. 
Mansfield, E. (1981) 'Composition of R\&D expenditures: relationship to size of firm, concentration and innovative output', The Review of Economic and Statistics, Vol. 63, No. 4, pp.610-615.

Masso, J. and Vahter, P. (2008) 'Technological innovation and productivity in late-transition estonia: econometric evidence from innovation surveys', The European Journal of Development Research, Vol. 20, No. 2, pp.240-261.

Mathew, N. (2012) 'Drivers of Firm Growth: Micro-Evidence from Indian Manufacturing', LEM Working Paper Series, 2012/24.

McCann, P. and Ortega-Argilés, R. (2015) 'Smart specialization, regional growth and applications to European Union cohesion policy', Regional Studies, Vol. 49, No. 8, pp.1291-1302.

Nelson, R.R. (Ed.) (1993) National Innovation Systems: A Comparative Analysis, Oxford University Press, Oxford.

Netter, J.M. and Megginson, W.L. (2001) 'From state to market: a survey of empirical studies on privatization', Journal of Economic Literature, Vol. 39, No. 2, pp.321-389.

Ó hUallacháin, B. and Leslie, T.F. (2007) 'Rethinking the regional knowledge production function', Journal of Economic Geography, Vol. 7, No. 6, pp.737-752.

OECD (1999) Managing National Innovation Systems, OECD Press, Paris.

Pardey, P.G. (1989) 'The agricultural knowledge production function: an empirical look', The Review of Economics and Statistics, Vol. 71, No. 3, pp.453-461.

Pavlov, R. (2012) 'Conceptual fundamentals of the long wave theory and the innovative potential of the Russian economy', International Journal of Innovation and Regional Development, Vol. 4, Nos. 3-4, pp.338-348.

Perret, J.K. (2013) Knowledge as a Driver of Regional Growth in the Russian Federation, Springer, Heidelberg.

Perret, J.K. (2015) 'Knowledge spillovers via patent citations across the regions of the Russian federation - evidence from European patent data', International Journal of Innovation and Regional Development, Vol. 6, No. 4, pp.376-408.

Perret, J.K. (2017) 'Re-evaluating the knowledge production function for the regions of the Russian federation', Journal of the Knowledge Economy, DOI: 10.1007/s13132-017-0475-z.

Podmetina, D., Vaatanen, J. and Smirnova, M.M. (2011) 'Open innovation in Russian firms: an empirical investigation of technology commercialization and acquisition', International Journal of Business Innovation and Research, Vol. 5, No. 3, pp.298-317.

Ponds, R., van Oort, F. and Frenken, K. (2010) 'Innovation, spillovers and university-industry collaboration: an extended knowledge production function approach', Journal of Economic Geography, Vol. 10, No. 2, pp.231-255.

Porter, M.E. (1990) The Competitive Advantage of Nations, Macmillan, London.

Quah, D.T. (1995) Regional Convergence Clusters Across Europe, Centre for Economic Performance Discussion Paper, p.274.

Ramani, S.V., El-Aroui, M-A. and Carrere, M. (2008) 'On estimating a knowledge production function at the firm and sector level using patent statistics', Research Policy, Vol. 37, No. 9, pp.1568-1578.

Ranga, L.M., Debackere, K. and von Tunzelmann, N. (2003) 'Entrepreneurial universities and the dynamics of academic knowledge production: a case study of basic vs. applied research in Belgium', Scientometrics, Vol. 58, No. 2, pp.301-320.

Rodríguez, J.C. and Navarro-Chavez, C.L. (2015) 'A system dynamics model of science, technology and innovation policy to sustain regional innovation systems in emerging economies', International Journal of Innovation and Regional Development, Vol. 6, No. 1, pp.7-30.

Rodríguez, J.C., Navarro-Chavez, C.L. and Gomez, M. (2014) 'Regional innovation systems in emerging economies: evidence of system failures for innovation', International Journal of Innovation and Regional Development, Vol. 5, Nos. 4-5, pp.384-404. 
Roper, S. and Hewitt-Dundasa, N. (2015) 'Knowledge stocks, knowledge flows and innovation: evidence from matched patents and innovation panel data', Research Policy, Vol. 44, No. 7, pp.1327-1340.

Rosstat (2003) Regions of Russia 2003/Regiony Rossii [online] http://www.gks.ru (accessed 16 May 2016).

Rosstat (2008) Regions of Russia 2008/Regiony Rossii [online] http://www.gks.ru (accessed 16 May 2016).

Rosstat (2011) Regions of Russia 2011/Regiony Rossii [online] http://www.gks.ru (accessed 16 May 2016).

Rosstat (2012) Regions of Russia 2012/Regiony Rossii [online] http://www.gks.ru (accessed 16 May 2016).

Rothwell, R. (1989) 'Small firms, innovation and industrial change', Small Business Economics, Vol. 1, No. 1, pp.51-64.

Roud, V. (2007) Firm-Level Research on Innovation and Productivity: Russian Experience, ISSEK Working Paper.

Savin, I. and Winker, P. (2012) 'Heuristic optimization methods for dynamic panel data model selection: application on the Russian innovative performance', Computational Economics, Vol. 39, No. 4, pp.337-363.

Schumpeter, J.A. (1911) Theorie der wirtschaftlichen Entwicklung, eine Untersuchung uber Un-ternehmergewinn, Kapital, Kredit, Zins und den Konjunkturzyklus, Harvard University Press, MA.

Silva, A. Afonso, O. and Africano, A.P. (2010) 'Learning-by-exporting: what we know and what we would like to know', The International Trade Journal, Vol. 26, No. 3, pp.255-288.

Stephan, P., Audretsch, D. and Hawkins, R. (2000) 'The knowledge production function lessons from biotechnology', International Journal of Technology Management, Vol. 19, pp.165-178.

Tompson, W. (2006) 'A frozen Venezuela? The resource curse and Russian politics', in Ellman, M. (Ed.): Russia's Oil and Natural Gas: Bonanza or Curse?, pp.189-212, Anthem Press, London.

Torkkeli, M.T. Podmetina, D., Ylä-Kojola, A-M. and Väätänen, J. (2009) 'Knowledge absorption in an emerging economy - the role of foreign investments and trade flows in Russia', International Journal of Business Excellence, Vol. 2, Nos. 3-4, pp.269-284.

Varga, A. (2000) 'Local academic knowledge spillovers and the concentration of economic activity', Journal of Regional Science, Vol. 40, No. 2, pp.289-309.

VCIOM (2012) About Us [online] http://wciom.com (accessed 16 May 2016).

Verspagen, B. and Schoenmakers, W. (2004) 'The spatial dimension of patenting by multinational firms in Europe', Journal of Economic Geography, Vol. 4, No. 1, pp.23-42.

Wagner, J. (2006) International Firm Activities and Innovation Evidence from Knowledge Production Functions for German Firms, MPI Discussion Papers on Entrepreneurship, Growth and Public Policy, 1506.

Wagner, J. (2007) 'Exports and productivity: a survey of the evidence from firm-level data', The World Economy, Vol. 30, No. 1, pp.60-82.

Wang, E. and Huang, W. (2007) 'Relative efficiency of R\&D activities: a cross-country study accounting for environmental factors in the DEA approach', Research Policy, Vol. 36, No. 2, pp.260-273.

WIPO (2012) Patent System in Russia [online] http://www.wipo.int/edocs/lexdocs/laws/en/ ru/ru067en.pdf (accessed 16 May 2016).

Wu, Y-M. (2009) 'An empirical analysis of R\&D cooperation and regional knowledge spillovers based on knowledge production function', Studies in Science of Science, 2009-10.

Yuri Levada Analytical Center (2012) Levada Center [online] http://www.levada.ru/en/about-us/ (accessed 16 May 2016). 
Zabala-Iturriagagoitia, J.M., Voight, P., Gutierrez-Gracia, A. and Jimenez-Saez, F. (2007) 'Regional innovation systems: how to assess performance', Regional Studies, Vol. 41, No. 5, pp.661-672.

Zemtsov, S. Barinova, V. Pankratov, A. and Kutsenko, E. (2016a) 'Potential high-tech clusters in Russian regions: from current policy to new growth areas', Foresight and STI Governance, Vol. 10, No. 3, pp.34-52.

Zemtsov, S. Muradov, A., Wade I. and Barinova, V. (2016b) 'Determinants of regional innovation in Russia: are people or capital more important', STI Governance, Vol. 10, pp.29-42.

Zucker, L.G., Darby, M.R., Furner, J., Liu, R.C. and Ma, H. (2007) 'Minerva unbound: knowledge stocks, knowledge flows and new knowledge production', Research Policy, Vol. 36, No. 6, pp.850-863.

\section{Notes}

1 This article is furthermore important as it focuses on the social dimension of the RIS, an aspect that usually is not considered in detail.

2 In this context, they offer a more compact approach than, for example, Carvalho et al. (2015) that also can be applied to NIS and still allows for the results to be comparable. However, due to its simplicity the approach necessarily will be less detailed than the aforementioned approach by Carvalho et al. (2015).

3 Especially in Lundvall (1992), the close link of innovation systems to clusters and innovative milieus can be seen, as both Porter (1990) and Carmagni (1991) are cited in Lundvall's definition of a NIS.

4 Officially, an application should be processed after 18 months.

5 See respective reports by Yuri Levada Analytical Center (2012) or VCIOM (2012).

6 The implemented panel estimator uses the $\mathrm{R}$ package rqpd which has been developed by Koenker in accordance to the version proposed in Koenker (2004).

7 It can be noted that this study is not the first to implement panel quantile estimation in this context, however, besides the study by Mathew (2012) no comprehensive study following the same research structure can be mentioned. Additionally, while Mathew (2012) implements this method, it is not used in the context of knowledge production and this study is also the first to apply it to Russian data.

8 Note that for reasons of data availability we only consider the basic version of the USA KPF herein. 